The challenges of using structured risk assessment instruments in forensic psychiatric care

Sara Levin 


\section{The challenges of using structured risk assessment instruments in forensic psychiatric care}

Sara Levin

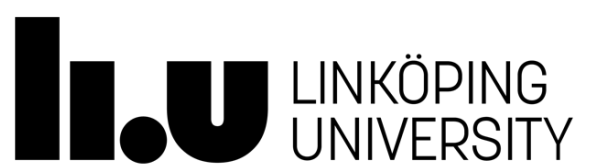

Department of Medical and Health Sciences

Linköping University, Sweden

Linköping 2019 
(C)Sara Levin, 2019

Published article has been reprinted with the permission of the copyright holder.

Printed in Sweden by LiU-Tryck, Linköping, Sweden, 2019

ISBN 978-91-7685-120-3

ISSN $0345-0082$ 
I dedicate this thesis to those who struggle with mental illness

Confusion is the beginning of wisdom, Kahlil Gibran 



\section{CONTENTS}

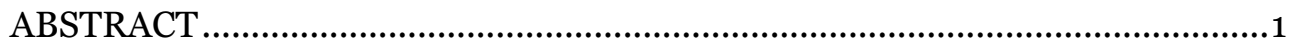

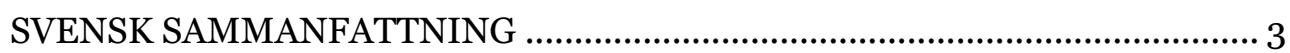

LIST OF PAPERS .............................................................................. 5

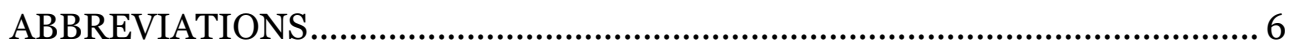

PREFACE ............................................................................................ 7

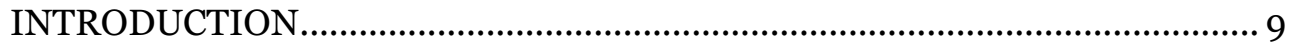

Forensic psychiatric care............................................................. 9

The role of risk assessments in forensic psychiatric care ....................... 10

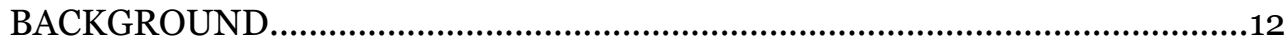

Basic aspects of structured risk assessments in forensic psychiatric

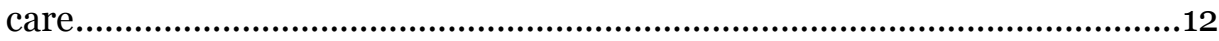

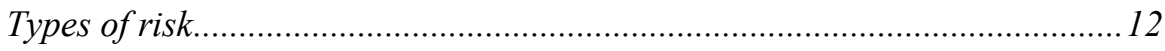

Risk and protective factors for violence and other adverse events................. 13

Stakeholders in risk assessments ................................................................ 13

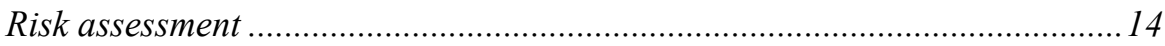

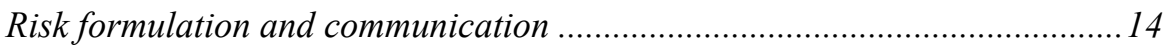

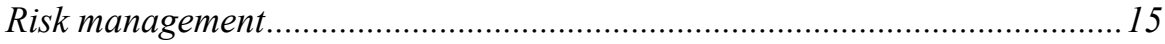

Development of different approaches to risk assessment within forensic psychiatric care............................................................16

The unstructured clinical approach ........................................................ 16

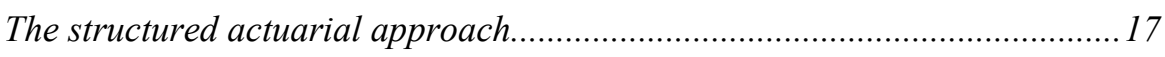

The structured professional judgement approach....................................... 18

Current use of structured risk assessment instruments ..........................20

Patient participation and perspectives .................................................... 21

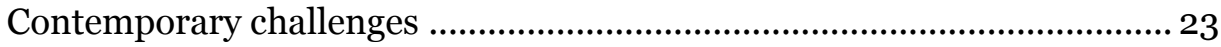

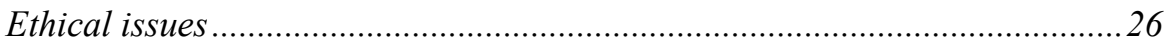

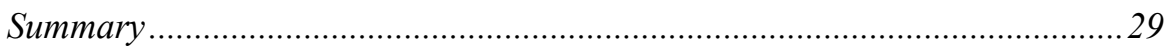


Rationale

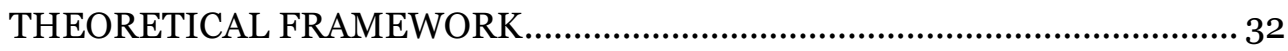

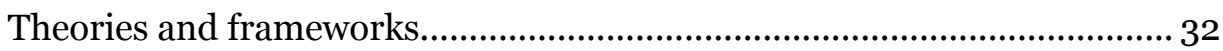

Consolidated Framework for Implementation Research (CFIR)......................32

Diffusion of Innovation Theory .......................................................................... 33

Self-Determination Theory ............................................................................ 33

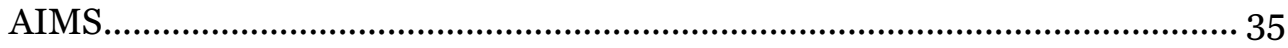

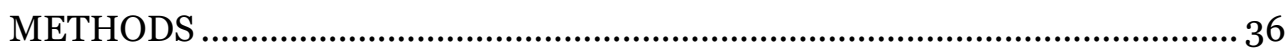

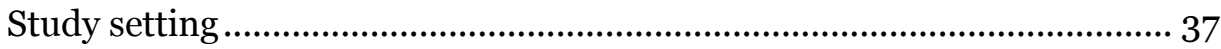

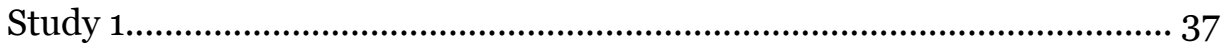

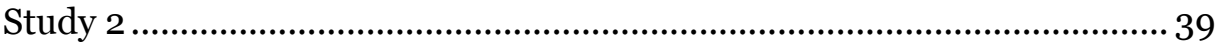

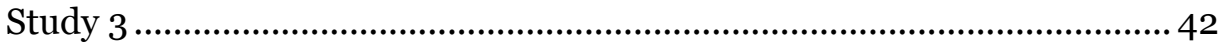

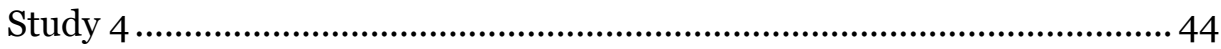

Methodological and ethical considerations...................................................46

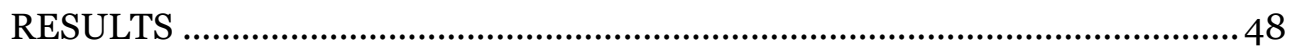

Implementation determinants for structured risk assessment instruments in clinical settings (study 1).....................................................48

Staff perceptions of facilitators and barriers to the use of a short-term risk assessment instrument in forensic psychiatry (study 2) ...................... 52

Adherence to planned risk management interventions according to patient records (study 3) ................................................................................ 55

Forensic patients' perceptions of risk-increasing and risk-decreasing factors for violence (study 4) ........................................................................ 57

Summary of thesis findings ...................................................................... 58

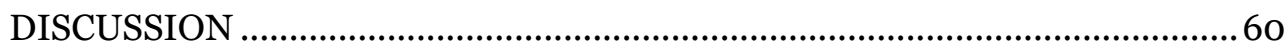

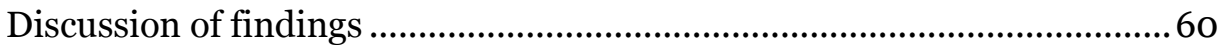

Determinants influencing implementation and clinical use of SRAIs in

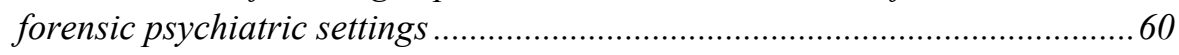

Clinical use of structured risk assessment instruments by fidelity to risk management plans

Patient perspectives of risk-increasing and risk-decreasing factors for

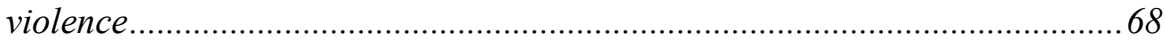

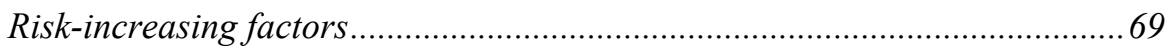

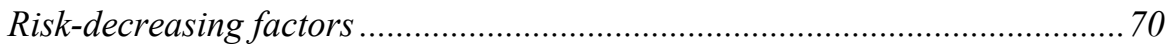

Patient participation ……………………………………............................ 71

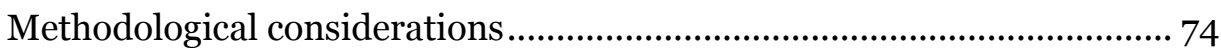




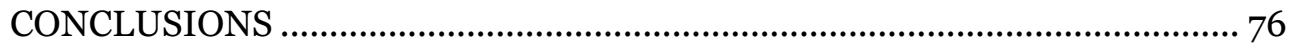

IMPLICATIONS FOR FURTHER RESEARCH …......................................... 78

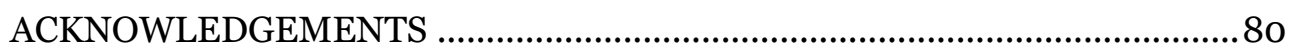

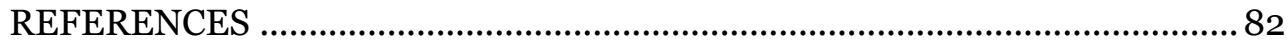





\section{ABSTRACT}

Background: The purpose of psychiatric forensic care is to provide treatment for mentally ill offenders and to prevent future acts of violence and other adverse events. During care, the type of restrictions of freedom, the patient's continuous need for involuntary treatment and readiness for discharge, are continuously evaluated based on the assessment of risk the patient pose to themselves and others as well as the progress achieved with treatment. The use of structured risk assessment instruments is recommended in clinical guidelines to assess such risks. However, unstructured clinical assessments, considered to be less valid, are often used in clinical practice. There is insufficient research evidence concerning several aspects related to the clinical use of structured risk assessment instruments in terms of guiding the planning and realization of care and risk management interventions. There is also a lack of knowledge about what patients themselves perceive to be mediating factors for their use of violence.

Overall aim: The overarching aim of this thesis was to investigate the implementation and use of structured risk assessment instruments to prevent violence and other adverse events in forensic settings and to improve understanding of the factors that influence such events among forensic patients.

Methods: Several methods were used for data collection and data were analysed by different types of content analysis. In the first paper, a systematic review of previous research studies on implementation determinants for structured risk assessment instruments in forensic settings was conducted to investigate implementation determinants for such instruments. The second paper evaluates a pilot project of the implementation of a structured risk assessment instrument at a forensic clinic in Östergötland using focus group interviews with staff members who had used the instrument. Their perceptions of the instrument and barriers and facilitators to its implementation and clinical use were investigated. The third paper investigated the actual clinical use of structured risk assessments to guide the planning and realization of care and risk management interventions documented in forensic patients' records. In the fourth paper, patient perspectives of factors increasing and decreasing the risk for violence were investigated by individual semi-structured interviews with forensic patients. 
Results: There is a wide variety of determinants for the implementation and clinical use of structured risk assessment instruments, which make such missions complicated. The determinants relate to the characteristics of the implementation object, characteristics of users, the inner setting in which the implementation occurs and the implementation process. Limiting the need to change current routines, and hence the strain on the organization by reducing complexity, and the need for resource allocation seem especially important. Most of the planned risk management interventions in structured risk assessments were realized according to patient records. However, structured risk assessments largely overlap with unstructured risk assessments in terms of planned care and risk management interventions. Noteworthy, most of the interventions realized were not documented as planned. Forensic patients described several risk factors that increased and decreased their use of violence. These factors related to themselves, external influences, social and relational aspects and situational factors. Most patient accounts of mediating factors overlapped with those listed in commonly used risk assessment instruments and previous research. Additional factors identified by patients related to the outer context and interpersonal aspects.

Conclusions: There are many barriers and facilitators to the implementation and use of structured risk assessment instruments, implying the need for a multifaceted approach to address determinants at several system levels. Considering the clinical context is important when selecting a structured risk assessment instrument to be implemented, but also the complexity of the instrument, the required change of routines and the provision of continuous resources and interventions to achieve and maintain clinical use. Despite the many barriers, there is evidence of clinical use of both unstructured clinical and structured risk assessments in terms of informing and guiding care and risk management interventions. The large overlap, however, makes it difficult to draw definite conclusion about which type of assessment actually influenced the interventions that were realized. Realized care and risk management interventions are most often not documented as planned. This increases the risk of subjective decisions and provision of interventions, which also make such interventions difficult to evaluate. Forensic patients are actively managing their risk of violence and are capable of identifying and communicating many different mediating factors for their violence risk. They are knowledgeable and important stakeholders and should be involved in their own risk assessments, as well as in research. 


\section{SVENSK SAMMANFATTNING}

Bakgrund: Syftet med rättpsykiatrin är att tillhandahålla vård för att behandla psykisk sjukdom hos psykiskt sjuka lagöverträdare och förhindra dem från återfall i brott och andra skadliga beteenden. Under vården utvärderas risken för dessa händelser, men även patientens behandlingsprogress, fortlöpande. Bedömningarna kan påverka vård och riskhanteringsinsatser. Kliniska riktlinjer rekommenderar att man använder strukturerade riskbedömningsinstrument för att bedöma sådana risker. Ostrukturerade kliniska bedömningar, som anses vara mindre tillförlitliga, används emellertid ofta inom rättspsykiatrin. Det finns otillräcklig forskningsevidens kring flera aspekter relaterad till klinisk användning av strukturerade riskbedömningsinstrument, såsom att vägleda planering av vård och riskhanteringsinsatser. Det finns också brist på kunskap om vilka interventioner som kan förebygga våld och vad patienterna själva uppfattar som påverkansfaktorer för deras användning av våld.

Övergripande mål: Det övergripande målet med denna avhandling var att undersöka implementering och klinisk tillämpning av strukturerade riskbedömningsinstrument för att förebygga våld och andra skadliga händelser och att förbättra förståelsen för faktorer som påverkar sådana händelser enlig rättspsykiatriska patienter.

Metoder: Flera olika metoder för datainsamling och dataanalys användes för att undersöka genomförandet och användningen av strukturerade riskbedömningsinstrument och patienternas perspektiv. En systematisk granskning av tidigare forskningsstudier om implementeringsdeterminanter för strukturerade riskbedömningsinstrument i rättspsykiatriska verksamheter genomfördes i studie 1. Ett pilotprojekt med implementering av ett strukturerat riskbedömningsinstrument vid en rättspsykiatrisk klinik utvärderades i den andra studien genom fokusgruppsintervjuer med 18 användare av instrumentet. För att undersöka den faktiska kliniska användningen av strukturerade riskbedömningsinstrument i termera av att vägleda planering av vård- och riskhanteringsinterventioner granskades rättpsykiatriska patienters journaler i den tredje studien. I den fjärde studien studerades rättspsykiatrisk patienters perspektiv på riskökande och riskminskande aspekter för våld genom individuella halvstrukturerade intervjuer.

Resultat: Det finns en mängd olika påverkansfaktorer för implementering och klinisk användning av strukturerade riskbedömningsinstrument. Dessa kan relateras till implementeringsobjektets egenskaper, använda- 
rens egenskaper, den inre kliniska miljön och implementeringsprocessen. Att begränsa behovet av förändring och därmed belastningen på organisationen och användarna av instrumentet genom att minska komplexiteten och behovet av resursallokering verkar särskilt viktigt. De flesta av de planerade riskhanteringsåtgärderna, både i ostrukturerade kliniska och strukturerade riskbedömningar, genomfördes enligt dokumentation i patientjournalerna (studie 3). En stor överlappning hittades mellan de två typerna av bedömningar vad gäller planerad vård och riskhantering. Detta indikerar en klinisk användbarhet av båda typerna av bedömningar. De flesta av de genomförda vård- och riskhanteringsinsatserna har dock inte dokumenterats som planerade, vilket indikerar att majoriteten av insatserna baseras på subjektiva spontana bedömningar. Rättspsykiatriska patienter beskrev ett flertal olika riskökande och riskminskande faktorer för deras användning av våld. Dessa faktorer relaterade till dem själva, yttre påverkan, sociala, relationella och situationella omständigheter. De flesta faktorer överensstämmer med de som listas i vanligt förekommande riskbedömningsinstrument och tidigare forskning.

Slutsatser: Många olika hinder och underlättande faktorer är relevanta för införande och klinisk användning av ett strukturerat riskbedömningsinstrument. Detta innebär att man behöver ett mångfacetterat tillvägagångssätt som beaktar aspekter på flera olika systemnivåer om man ska lyckas implementera och använda sådana instrument i en klinisk vardag. Trots de många barriärerna tyder resultatet på att det finns en faktisk klinisk användning av både ostrukturerade kliniska och strukturerade riskbedömningar när det gäller att informera och vägleda vård och riskhantering. Den stora överlappning gör det emellertid svårt att dra en bestämd slutsats om vilken typ av bedömning som faktiskt påverkat de realiserade insatserna. Planeringen av genomförda vård- och riskhanteringsåtgärder är oftast inte dokumenterade i journalen. Detta ökar risken för subjektivitet och godtyckliga beslut vid tillhandahållande av insatser, vilket också gör sådana insatser svåra att utvärdera. Rättpsykiatriska patienter arbetar aktivt för att hantera sin risk för våld och är kapabla att identifiera och kommunicera många olika påverkansfaktorer för den risken. De är kunniga och viktiga intressenter i sin egen kliniska riskbedömning, såväl som i forskning. 


\section{LIST OF PAPERS}

1. Levin, S.K., Nilsen, P., Bendtsen, P., Bülow, P. (2015). Structured risk assessment instruments: a systematic review of implementation determinants. Psychiatry, Psychology and Law 23, 602-608.

http://doi.org/10.1080/13218719.2015.1084661

2. Levin, S.K., Nilsen, P., Bendtsen, P., Bülow, P. (2018). Staff perceptions of facilitators and barriers to the use of a short-term risk assessment instrument in forensic psychiatry. Journal of Forensic Psychology Research and Practice. 18, 199-228.

http://doi.org/10.1080/24732850.2018.1466260

3. Levin, S.K., Nilsen, P., Bendtsen, P., Bülow, P. (2019). Adherence to planned risk management interventions in Swedish forensic care: what is said and done according to patient records. International Journal of Law and Psychiatry 64, 71-82.

https://doi.org/10.1016/j.ijlp.2019.02.003

4. Levin, S.K., Nilsen, P., Bendtsen, P., Bülow, P. (2019) Risk-increasing and Risk-reducing Factors for Violence - A Qualitative Study of Forensic Patients' Perceptions. Manuscript. 


\section{ABBREVIATIONS}

ARAI Actuarial risk assessment instrument

CFIR Consolidated Framework for Implementation Research (Damschroder et al., 2009)

HCR-2O Historical, Clinical and Risk Management - 20 (Webster et al., 1997), HCR-20 version 3 (Douglas et al., 2013)

SPJ Structured professional judgement

SPJI Stuctured professional judgement instrument

SRAI Structured risk assessment instrument

SRA Structured risk assessment

SAPROF Structured Assessment of Protective Factors for Violence Risk (de Vogel et al., 2012)

SAVRY Structured Assessment of Violence Risk in Youth (Borum et al., 2006)

START Short Term Assessment of Risk and Treatability assessment instrument (Webster et al., 2004; Webster et al., 2010)

SVR-20 Sexual Violence Risk -20 assessment instrument (Boer et al., 1997)

SRP Stalking Risk Profile (MacKenzie et al., 2009)

RSVP Risk of Sexual Violence Protocol (Hart et al., 2003)

UCJ Unstructured clinical judgement approach 


\section{PREFACE}

The ambition to understand mental illness and why people sometimes act violently emerged during my training to become a psychologist and inspired my choice to work within forensic psychiatry. Providing treatment to patients to help them recover from mental illness and to prevent adverse events are at the core of forensic psychiatric care. The rights and needs of the patients as well as the safety of others need to be considered. Using structured risk assessment instruments to assess the risk of violence and other adverse events, and being part of care teams trying to prevent such events in collaboration with patients, soon became part of my everyday work.

People can be harmful to themselves and others for many different reasons. The risk of violence and other types of adverse events can also change over time and depend on the current circumstances. Identifying a future risk and preventing it from occurring is inevitably a complex matter. The consequences of adverse events are often devastating and irreversible for the perpetrators, victims, family members as well as for the professional care givers. There are also consequences for the community in terms of financial costs, feelings of anxiety, insecurity or fear, reduced faith in psychiatric care and how they perceive and treat mentally ill offenders.

The pitfalls are many, and understanding and preventing adverse events can go awry in many different ways. Insufficient understanding of or an underestimation of risk can lead to use of risk management interventions that fail to address the specific risks and needs of the individual. This might result in incidents. On the other hand, overestimating risk and being overly cautious might reduce the risk of violence, but it may occur at the expense of patients being incarcerated for a longer time and with more restrictions than warranted. Resources are often limited, and allocating staff and treatment resources to patients who do not need them can also mean that someone else who does need them has to wait for such interventions. Restricting someone's rights and freedom based on an assessment of the risk they could pose to others in the future is of course also ethically complicated.

I have experienced occasions of structured risk assessments being used to inform and guide staff and patients to successful prevention of violence. I have also experienced that such assessments remain unused in patient records. Successful management of violence is of course also not only a result of care and risk management interventions provided by profession- 
al care givers. Patients are often actively striving and struggling to understand and manage their own risk of acting out in violence.

Real-life experiences in forensic psychiatric care sparked my interest in trying to understand more about the barriers and facilitators of the clinical use of structured risk assessments to prevent violence and other adverse events as well as the patient perspectives on factors that contribute to or inhibit violence. This $\mathrm{PhD}$ thesis is the product of this endeavour. 


\section{INTRODUCTION}

A short introduction to forensic psychiatric care and the purpose of using structured risk assessment instruments (SRAIs) to prevent adverse events are provided here.

\section{Forensic psychiatric care}

Definitions of forensic settings often refer to forensic psychiatric care facilities (secure settings as well as community settings), courts and other legal institutions, prisons and/or correctional services (Singh et al., 2011). This thesis focuses on forensic psychiatric services and the provision of care to mentally ill offenders, even though related populations such as psychiatric inpatients and correctional populations are sometimes used as reference because these populations overlap (World Health Organization, 2005; Annual Forensic Report, 2016, 2017; Fazel et al., 2016; Kriminalvårdens klientkartläggning, 2013).

People who commit crimes while influenced by a severe mental illness are sentenced by court to forensic care, a form of involuntary psychiatric care provided in a locked secure setting (Socialdepartementet, SFS 2017:374). It is the court that commonly decides the level of security, restrictions of freedom and termination of the involuntary care (Annual Forensic Report, 2016, 2017).

Forensic mental health patients are most often men with a major mental illness such as psychosis, personality disorder or a substance use disorder (Annual Forensic Report, 2016, 2017). Forensic mental health patients have often been committed to other institutions before being sentenced to forensic care, such as secure psychiatric care or prison/correctional services (Nedopil, 2009). After discharge, they are also often in need of continuous psychiatric care and sometimes need to be committed to psychiatric inpatient care. Secure psychiatric inpatient services house patients in need of care due to mental illness and at risk of doing harm to themselves or others. On occasion, such patients cannot be treated safely there and must be transferred to secure forensic mental health clinics for a period of time (SOSFS 2008:18).

Forensic psychiatric settings house somewhat diverse populations in different countries due to differences in legislation (Dressing and Salize, 
2004). Previous research is inconclusive regarding whether the predictive validity of different risk assessment instruments differs depending on the characteristics of the population assessed, but there seems to be some evidence of potential differences depending on age, ethnicity and gender (Singh et al., 2011), raising the question of the generalizability of research findings between and within different clinical and national populations. Nedopil (2009) concludes that the research in forensic psychiatry has become more international in recent decades, but that more international research is needed to understand the differences and similarities of forensic psychiatry in different countries.

\section{The role of risk assessments in forensic psychiatric}

\section{care}

The overall purpose of forensic care is to provide treatment and risk management interventions to support patients to recover from the mentall illness, prevent future adverse events and enable them to return to the community safely (Nedopil, 2009).

During care, the level and type of restrictions of freedom, the patient's continuous need for involuntary treatment and readiness for discharge are continuously evaluated based on assessment of the risk the patient poses to self and others as well as the progress achieved with treatment. The forensic patient should not be subjected to more treatment and restrictions than necessary (in terms of time, intensity and frequency) to maintain a reasonable level of security (SOSFS 2008:18). Forensic care providers and the courts have to continuously assess and balance the risks, needs and the rights of individual patients and the safety of others (Department of Health, 2007).

In order to accomplish this, risk assessment of what could cause a patient to act violently in the future needs to be conducted to know how to possibly prevent it from happening. Predicting what people will do in the future, as well as preventing such potential acts before they happen, is inevitably an extremely complex and difficult endeavour. Research suggests that the use of SRAIs can improve such assessments and are now part of evidence-based practice recommendations (Department of Health, 2007; NICE, 2007; Risk Management Authority, 2006). SRAIs have been developed for and implemented and used in forensic mental health services, secure psychiatric in-care services and correctional services to assess the risk of adverse events. Much of the research of risk assessment instruments comes from these different types of services. 
When conducting studies of SRAI and their implementation in clinical settings (studies 1 and 2), inclusion of all these services were deemed warranted. Because generalizing findings from different clinical populations can be problematic (Singh et al., 2011), studies 3 and 4 were restricted to research on the forensic psychiatric population. 


\section{BACKGROUND}

This chapter provides the background to the studies conducted as part of this $\mathrm{PhD}$ thesis. Basic aspects of and approaches to the implementation and clinical use of SRAIs in forensic psychiatric settings to prevent violence among mentally ill offenders are described.

\section{Basic aspects of structured risk assessments in forensic psychiatric care}

Definitions of aspects and procedures that can be related to risk assessments within forensic psychiatric care are outlined below, including the type of risk, risk and protective factors, stakeholders, risk assessment, risk formulations and communication and risk management.

\section{Types of risk}

Depending on the specific clinical and juridical setting and clinical situation, a risk assessment can have slightly different focus and include one or several different types of risk in the evaluation. Hence, risk can refer to a diverse range of aspects. Adverse events such as victimization, relapse in substance abuse, unauthorized leave, self-harm and self-neglect can be considered. In clinical settings, the risk is usually focused on the risk of violence to oneself and others. Woods and Lasiuk (2008) conclude that risk is often understood and measured in many different ways, making it sometimes difficult to compare research findings.

Researchers have defined violence as "actual, attempted, or threatened harm to a person or persons" (Scurich, 2016). When applying decision theory, violence can be understood as a voluntary behaviour and a conscious decision, involving going from having a goal, to intent, to action. Hence, the use of violence is a choice and rational in the sense that it has involved thinking. However, it not necessarily logical or correct (Hart et al., 2016). Hart et al. (2016) describe three main aspects influencing an individual's choice to use violence: motivators (aspects related to motives or reasons, perceived benefits); disinhibitors (circumstances that diminish inhibitions and the perceived potential negative consequences); and destabilizers (circumstances that diminish the ability to think clearly, to accurately perceive the circumstances, to consider alternatives, or weigh potential costs and benefits). 


\section{Risk and protective factors for violence and other adverse events}

A risk factor is associated with an increase in the likelihood or predisposition to future violent behaviour (or any other identified adverse event). Protective factors in the context of forensic risk assessments are circumstances or resources within the individual or outer setting that have some sort of preventive or risk-decreasing effect for future violence or adverse events. The connection is not necessarily causal and different risk and protective factors can interact in different ways with different individuals to increase or reduce the risk of violence. The absence of a risk factor does not necessarily count as a protective factor and vice versa. That is, if a particular risk factor is absent, it simply means that risk is not increased, not that risk is decreased (Scurich, 2016).

Moderating factors for violence can be categorized according to whether they are static (i.e. historical and unchanging), stably dynamic (modifiable but unlikely to change), and acutely dynamic (modifiable and likely to change) (Scurich, 2016). Dynamic risk factors refer to risk factors susceptible to change (spontaneously or by interventions) and refer to a state rather than a trait. The changeable aspects of dynamic factors mean they are receptive to treatment interventions and can be used to evaluate change. Examples of dynamic factors are impulsiveness, negative affectivity, psychosis, antisocial attitudes, substance use and related problems, interpersonal relationships, and treatment alliance and adherence (Douglas and Skeem, 2005), as well as lack of insight, violent ideation, current symptoms of major mental illness, affective, behavioural or cognitive instability (Douglas et al., 2013).

Risk and protective factors can also be divided into categories based on time perspectives: historical factors, present clinical factors and future risk factors (Douglas et al., 2013).

\section{Stakeholders in risk assessments}

Depending on the forensic clinical settings, the people being assessed can be referred to as patients, interns, service users or the more overarching term, mentally ill offenders. Within forensic care, the term patients are often used. Risk assessments can be conducted by researchers, professional risk assessors or clinical practitioners of diverse professional disciplines. Besides patients and risk assessors, clinical staff and other professional service providers, potential victims, legal representatives and the community can be considered as stakeholders in risk assessments (Hart et al., 2016). 


\section{Risk assessment}

Risk assessment can be referred to as a tool, instrument, method or procedure, depending somewhat on the level of predefined systemization that is used to assess risk. A risk assessment includes a process of collecting and interpreting relevant information and making an assessment of a specified type of risk. This process can be unstructured or structured to some extent. A structured risk assessment (SRA) often has several different aims, the main one in secure forensic settings being to prevent violence or other type of adverse events by guiding risk management. SRA can also aim to enhance accountability, protect the rights of patients and offenders, minimize professionals' exposure to liability by ensuring transparency and consistency (Hart et al., 2016), guiding allocation of resources and using the least amount of restrictions in the care of patients (Judges et al., 2016).

\section{Risk formulation and communication}

How a risk assessment is formulated and communicated can affect how it is perceived and understood by different stakeholders. Risk formulation is recognized as a potentially important aspect of transferring a risk assessment to clinical practice in terms of risk management.

A risk formulation can include an estimation of the probability of a certain type of risk (usually in terms of level of risk), the severity/seriousness, imminence/time, mediating circumstances/risk situations, chronic and frequency. A description of potential victims as well as potential consequences can also be included. It is important to consider and express the timeframe for which the risk assessment is valid and under what circumstances it might need to be revised. A risk formulation can furthermore include a comment about the quality and quantity of the available information underpinning the assessment and on what level of certainty the risk can be expressed (Hart et al., 2016).

Risk can also be formulated by identifying and describing motivators, disinhibitors and destabilizers (Hart et al., 2016). A risk formulation uses historical and present information to make an informed assessment about the future. To support nuanced thinking of such aspects and possible future events, some suggest using so-called scenario planning, whereby some (2-6) different, possible, plausible, and realistic outcomes are defined. These could be defined as best case, worst case, repeat of previous violence, escalation of violent severity, a twist/change in the nature of the violence and a scenario in which the individual manages to desist from using violence/committing adverse actions (Hart et al., 2016). 


\section{Risk management}

For the risk assessment and the identification of risk factors to have any clinical meaning regarding prevention of violence, beyond the use of restrictions, it must be possible to subject the risk factors to interventions in a way that reduces this risk. The individual with the posed risk must be under some sort of supervision of those responsible for preventing the risk, and there must be a risk management plan in place, as well as sufficient allocation of resources (Monahan and Skeem, 2014). Douglas et al. (2013, p.5) provide the following definition:

Management is the process of taking action to gain or maintain control of a situation. In the case of violence risk, management comprises steps taken to mitigate risk through prevention, including early identification of and responses to any future violence.

Risk management interventions can be defined as any intervention aiming to reduce the risk of violence recidivism (Heilbrun, 1997). Such endeavour often focuses on mitigating risk-increasing factors and more recently also facilitating risk-decreasing preventive factors. Violence prevention within public health care can be focused on primary prevention strategies aimed at preventing violence before it happens, secondary prevention aimed at early detection and prevention of imminent violence, and tertiary prevention aimed at reducing the impact or minimize the harm of violence (Hallet et al., 2014). Different clinical and legal contexts, populations, gender and levels of assessed risk might affect which type of violence prevention perspective and risk management interventions that are used, warranted, allowed and available (Maguire et al., 2017; Kaunomäki et al., 2017). Violence prevention within forensic and inpatient psychiatric settings can include addressing all three types of these violence prevention perspectives, even though the extent to which this is done and the effectiveness of such strategies have not been investigated (Hallet et al., 2014). A wide range of risk management interventions usually need to be considered (Allnutt et al., 2013).

Douglas et al. (2013) and Doyle and Logan (2012) suggest the following main types of risk management interventions: monitoring, supervision, treatment and victim safety planning. Monitoring includes surveillance interventions and plans to continuously monitor risk factors and early warning signs to prevent relapse. Supervision includes control and involuntary restriction of the environment or setting, rights and freedom of the patient to limit exposure or access to circumstances related to risk of adverse events. Treatment includes, for example, different habilitative and rehabilitative interventions, psychopharmacological interventions, psychotherapy, psychosocial rehabilitation, as well as different types of assessments. Victim safety planning includes plans, recommendations and 
interventions to protect and support a potential victim (past or future) from harm.

Moreover, risk reduction is not only a function of risk management interventions provided by the external context and professional staff. Patients themselves are most often actively trying to prevent themselves from being violent, and previous research has revealed a wide variety of risk management strategies used by patients (Olsson et al., 2015; Whinship, 2014; Meehan et al., 2006; Johnson et al., 1997). Strategies such as selfmotivation, improving their self-esteem, improving their understanding, engaging in treatment and medication, managing feelings of aggression, acceptance of their situation, thinking about consequences and assuming responsibility, attending to warnings signs and avoiding use of substances are also used. Conflicts and escalation were mitigated by patients withdrawing to their rooms and trying to support a good climate on the ward. Seeking support from and opening up to staff was also mentioned. Forensic and psychiatric inpatients also advocate engaging in physical activities and being occupied with meaningful activities to prevent violence by reducing boredom, stress and frustration.

\section{Development of different approaches to risk assessment within forensic psychiatric care}

The development of different approaches to risk assessments in forensic psychiatric and other settings has been motivated by perceived methodological limitations and problems with clinical use.

\section{The unstructured clinical approach}

Initially, risk assessments in forensic psychiatric settings were carried out by clinicians, based on their clinical training and experience and the clinically available anecdotal information, without any predetermined systematic procedure. The strength of unstructured clinical risk assessments is the flexibility that allows the clinician to consider the current situation and what is relevant to the specific case and patient at the time of the assessment (Woods and Lasiuk, 2008). There are also practical benefits, such as lack of need for training and that it can be done quickly, because it does not require additional gathering of information. These benefits are important considering the time pressure and limitation of resources common in forensic psychiatry.

Because it is up to each clinician to intuitively decide which factors to consider, how much weight they have and how to combine them, important factors identified by research may be ignored. These assessments can be 
more influenced by human decision bias such as reliance on illusory correlations (i.e. believing there is a correlation between a particular risk factor and violence when no correlation exists); suboptimal weighting of risk factors (giving risk factors more or less weight than is appropriate); ignoring the generally low base rate of violence; influence of personal experiences; and believing that what is expected or wanted is more likely to occur (Scurich, 2016; Carrol, 2009). The lack of consistency, the subjective nature, as well as the lack of conclusive documentation of the sources of information considered and the basis for the conclusion, make such assessments difficult to evaluate in a systematic evidence-based way. Research has shown that unstructured risk assessments also have poor predictive validity and low inter-rater reliability (Singh et al., 2011).

Despite the critique of unstructured clinical risk assessments, these are not necessarily wrong (Murray and Thomson, 2010; Nijman, et al., 2002; Lidz et al., 1993). Unstructured clinical risk assessments are still commonly used in clinical settings today (Annual Forensic Report, 2016, 2017; Singh et al., 2016). The critique of unstructured risk assessment however motivated research on risk factors for violence and called for a need to remove the clinicians' own opinion from influencing these assessments. This resulted in second-generation actuarial risk assessment instruments (ARAIs) in the early 1990 .

\section{The structured actuarial approach}

This type of assessment is highly structured and is based on static risk factors for violence, derived from research, statistically associated with increased risk in large clinical populations. There is a fixed predetermined assessment procedure whereby a total score for the level of risk is derived by calculating numeric ratings of each predetermined factor. Some risk factors might be correlated moderately with violence, whereas some might be correlated highly. Different score cut-offs are set to a specific probabilistic level of risk; the assessor does not interpret the scores. The risk of assessor bias and subjectivity are reduced. ARAIs can be used to predict the statistical risk of specific large populations, making them suitable for use in research and perhaps in clinical/forensic settings where a single yes or no answer of high or low risk level is required (Scurich, 2016).

Actuarial assessments tend to ignore risk factors that do not occur commonly, but that might be highly relevant to a specific patient. The underreporting of different types of violence can also create uncertainty in the data underlying the actuarial factors (Scurich, 2016). The static nature of the factors also means that actuarial risk assessments are usually not susceptible to change and commonly cannot be used to guide risk management interventions, especially not for a specific individual. Because 
forensic settings usually include a treatment and risk prevention perspective, adjusted to each individual, the actuarial approach is often not clinically applicable (which also means it is rarely mentioned in this thesis). Department of Health (2007) in the United Kingdom recommends that an actuarial risk assessment should only be used as one part of an overall risk assessment and never as the only way of evaluating the risks posed by an individual service user. Despite the benefits of some predictive validity at the group level, such assessments have proved less relevant in clinical settings designed to prevent violence in individuals rather than predicting it (Hart et al., 2016).

The shortcomings of ARAIs led to a third generation of risk assessments in the mid-1990s, which took a more structured professional judgement (SPJ) approach by combining clinical assessment and research evidence of risk factors.

\section{The structured professional judgement approach}

Structured professional or clinical risk assessments, often shortened to (structured professional judgement [SPJ]), are based on evidence-based predefined factors derived from research and extant literature (Scurich, 2016); the clinician's experience and knowledge of the service user; and the service user's own view of their experience (Department of Health, 2007). The assessor evaluates the presence and relevance of each factor according to the individual's specific circumstances, using their own experience, knowledge and discretion. By going through the list of potentially mediating circumstances, the clinician avoids missing relevant information. The approach includes systematic gathering of information, assessment of risk, formulation and documentation of the basis for the conclusions and communication of the assessment to stakeholders. SPJ assessments aim to prevent the risk of adverse events by specifying risks and guiding individualized risk management, and are hence appropriate for use in forensic psychiatric settings.

SPJ assessments are based on factors supported by research evidence which might not include factors that the clinician or the service user consider relevant. Statistical information and research knowledge about risk factors relevant to a population might also not be relevant or applicable to a specific individual in a specific clinical situation (Monahan and Skeem, 2014). However, in the SPJ approach, the assessor is also usually encouraged to add factors and considerations they deem to be relevant to the individual but not commonly identified by previous research.

SPJ assessments require the assessor to have had training in the specific SPJ instrument (SPJI) and the thorough and often extensive procedure of gathering information can make them more time consuming and resource 
demanding than other approaches. It is also often difficult to evaluate the effectiveness of SPJIs, given their range of applications and the difficulty of measuring the difference between predictive validity and successful risk prevention by management. Being aware of a risk and not doing anything to prevent it goes against the purpose of providing forensic psychiatric care, and this makes randomized controlled studies difficult. Even SPJ risk assessments are vulnerable to subjective biases because the assessor intuitively combines the risk factors and arrives at a judgement about risk (Scurich, 2016).

The HCR-20, revised 2013 HCR-20 version 3 (Webster et al., 2013) is an SPJ instrument designed to predict the likelihood of violence in adults in different forensic, correctional and civil psychiatric settings. The HCR-20 Version 3 includes summary risk rating of low, moderate, or high risk as well as summary risk ratings for serious physical violence, and for imminent violence. There is however also options to indicate when any risks other than violence need to be considered (Douglas, 2014). The HCR-20 has been validated in inpatient and outpatient settings with forensic psychiatric, civil psychiatric and correctional populations and is the most widely used SRAI in the world (Douglas 2014). Research of the HCR-20 V3 so far has shown acceptable inter-rater reliability and moderate to high prediction of violence (Douglas \& Belfrage, 2014; Hogan \& Olver, 2016).

The structured risk assessment instrument, Short term assessment of risk and treatability (START, Webster, et al., 2004) provides guidance on health care and preventive measures, encompassing clinical, dynamic risk and protective factors. Additional relevant individual-specific risk and protective factors can be added. The START also includes assessment of several different types of incidents, e.g. violence against others, suicide, self-harm, self-neglect, being victimized, unauthorized leave and substance abuse. START is designed to be used in diverse settings (inpatient and outpatient) providing care for forensic, correctional and psychiatric populations and covers a wide range of adverse incidents (Nicholls, et al., 2011). Predictive validity of START has been demonstrated in previous research on forensic psychiatric patients (Doyle, et al., 2008; Nicholls, et al., 2006; Nonstad et al., 2010; O'Shea and Dickens, 2014; Webster, et al., 2004). The inclusion of short-term clinical, dynamic risk and protective factors and a variety of adverse events, mean it addresses specific evidence-based practice recommendations for risk assessments (NICE, 2007; Risk Management Authority, 2006).

The Structured Assessment of Protective Factors for Violence Risk (SAPROF) is an SPJ instrument that was developed to supplement the HCR-2O and similar instruments by adding protective factors for violence into the case formulations of adult violent and sexual offenders (de Vogel, et al., 2012). The SAPROF has been found to be a reliable and valid sup- 
plement to the HCR-20 Version 3 (de Vries Robbé, et al., 2015), with more accurate assessments being produced for violent rather than sexual recidivism. Research examining the SAPROF has demonstrated good inter-rater reliability and predictive validity for violent recidivism (de Vries Robbé, et al., 2011; de Vries Robbé, et al., 2015).

The term SRAI refers to risk assessment instruments with some level of structure, such as SPJ risk assessments and actuarial risk assessments. The term SPJI refers only to SPJ risk assessment instruments.

\section{Current use of structured risk assessment instruments}

The use of SRAIs in forensic psychiatric services has increased in many countries the last decades (Singh et al., 2011). There are more than 400 SRAIs available today, and in use on six continents (Singh et al., 2014b), covering different types of risk (violence towards others, self-harm, suicide, criminal reoffending, misuse of substances, absconding, victimization and neglect of self), different types of factors (historical, clinical, situational, future, static, dynamic, risk and protective), time perspectives (hours, days, weeks, months years), age of population (youth, adults), forensic settings (forensic psychiatric care, prison/correctional services, court/legal institution and police and probation services) and many different countries (Singh et al., 2011; Yang et al., 2010; Douglas et al., 2013; de Vogel et al., 2012; Borum et al., 2006; Webster et al., 2004; Boer et al., 1997).

When selecting which risk assessment instrument to use, aspects such as research on predictive validity, purpose of the assessment, the population being assessed, and the outcome of interest need to be considered (Singh et al., 2011); practical matters such as time requirements, costs, training needs and personal preference also need to be considered (Singh et al., 2014b). The level of predictive validity has been found to be similar among evidence-based SPJ instruments, probably because they rely on the similar risk factors (despite variations in item formulations and formats) (Yang et al., 2010), but the amount of research evidence to support the specific instruments might differ.

Research supports the predictive validity of SPJ risk assessment instruments to improve clinical risk judgements (Hogan and Olver, 2018; Persson et al., 2017; Vojt et al., 2013) and they are nowadays part of evidence-based practice recommendations (Department of Health, 2007; Risk Management Authority, 2006). However, the use of SPJIs has been questioned due to a high rate of false-positives, a lack of sufficient re- 
search evidence of predictive validity, clinical utility in guiding allocation of resources and ability to prevent recidivism and violence (Large et al., 2014; Wand, 2012). Despite the inconclusive research evidence for the actual clinical use and hence usefulness of SRAIs and several ethical issues, a method for assessing risk of future violence is often required in secure forensic clinical settings. Using SRAI s seems to be the best available alternative at the moment according to clinical guidelines (Department of Health, 2007).

\section{Patient participation and perspectives}

Nowadays, legislation and clinical guidelines force mental health services to provide opportunities for patients to actively participate in their own care in terms of making informed decisions and defining care needs and treatment, including risk assessment and management (SOU, 2004, 2006; Department of Health, 2007; NICE, 2013). Different levels of involvement has been observed, from merely informing the patient a risk assessment is being conducted and/or provided patients with a copy of the assessment, to an active participation by providing information/their perspective by being interviewed and/or doing rating of factors and defining a care and risk management plan (Gough, et al., 2015).

Involving and educating patients in the risk assessment and management process could potentially aid and improve such assessments (Skeem et al., 2013), improve patient satisfaction with care (Dixon, 2012; Livingston et al., 2013) and care outcome (Holliday et al., 2013). Patient involvement could also improve understanding of patient perspectives and encourage a sense of responsibility (Kroner, 2012), support resilience, confidence and self-management, promotes collaboration in their care plan and supports them in managing their own risk factors for violence (Gough, et al., 2015). Eidhammer et al. (2014) point out that some information can only be provided by patients themselves. Including patients in the risk assessment provides an opportunity to assess their insight, improve the relationship between patient and staff, stimulate mutual trust and improve adherence with treatment (Hall and Duperouzel, 2011).

However, patients' perceptions in forensic and psychiatric in-settings have traditionally often not been included in research or in clinical risk assessments (Judges et al., 2016; Gough, et al., 2015; Langan, 2010; Dixon, 2012; Kroner, 2012; Sullivan, 2005; Olsson et al., 2015) or in risk management intervention programmes (Eidhammer et al., 2014). Some patients are not even aware that assessments of their future risk for violence are being conducted and communicated to other stakeholders (Gough, et al., 2015; Dixon, 2012; Langan, 2010). 
Several different reasons for this lack of patient involvement in risk assessments have been suggested. A lack of routines of patient involvement (and therefore no expectations or pressure to do it), insufficient experience and confidence with staff to discuss issues of risk with patients, staff concerns about having a potentially distressing discussion with sometimes already acutely mentally ill patients (and making the situation worse), not wanting to risk to disrupt the therapeutic alliance, not expecting patient to be honest or knowlegable about their own risk, can make staff reluctant to involve patients in these assessments (Gough, et al., 2015; van den Brink et al., 2010; Hall and Duperouzel, 2011).

The possibility of honestly disclosing their true perceptions have also been questioned due to bias, psychiatric symptoms and expectations of negative consequences (Reynolds, et al., 2014; Holliday et al., 2013). Patients' perceptions that there is no point in expressing an opposing view because it will be not considered anyway have also found (Dixon, 2012). Not being able to be honest can cause frustration and a disrupt communication and relationship with care providers and became a barrier to a true recovery. It can also be a barrier to risk assessments as it rest on incorrect information and make patients focus on a superficial adjusting of their behavior rather than their mental health problems and offending (Reynolds, et al., 2014).

The ability of psychiatric patients to freely consent to participation in research without feeling pressured has also been discussed (Hall \& Duperouzel, 2011; Sullivan, 2005). There is some research evidence to suggest that mentally ill patients are capable of freely consenting to participation in research without feeling pressured (Magyar et al., 2012) and can successfully assess and communicate their own risk for future selfharm (Peterson et al., 2011; Ghio et al., 2011) and violence (Lockertsen et al., 2018; Skeem et al., 2013; Meehan et al., 2006; Roaldset and Björkly, 2010). Staff and researchers' willingness and ability to provide opportunities for patient involvement can influence patient's ability to participate in research (Storm and Edwards, 2013; Skeem et al., 2013). When patients are not restricted by thoughts of consequences to care, they can assess their risk potentially more accurately than unaided clinical risk assessment conducted by staff (Skeem et al., 2013).

Previous research on psychiatric inpatients' perceptions of risk and protective factors and efficient risk management strategies for violence shows that there are often some differences between patients on the one hand and staff or researchers on the other hand (Lanza and Kayne, 1995; Dixon, 2012; Ilkiw and Grenyer, 2003). Forensic and psychiatric patients are often more concerned about detrimental effects of medication, risks of institutionalization (Dixon, 2012), violence risk posed by other patients, isolation and loss of family contact, and inactivity (Kontio et al., 2013). 
Patients more often put emphasis on environmental and relational factors, communication, and a need to change a punitive culture and the importance of find a balance between security/control and treatment interventions (Dickens et al., 2013; Duxbury and Whittington 2005; Ilkiw and Grenyer, 2003). Staff behaviour is also mentioned more often by patients as a mediating factor for violence risk (Bensley et al., 1995). The availability of nurses to spend time with patients and who can quickly respond to early warning signs and use de-escalation techniques are further stressed by patients (Olsson et al., 2015; Whinship, 2014). Pulsford et al. (2013) found that both staff and patients perceived aggression as caused by a range of interpersonal factors (the patient's mental illness), external environmental factors (restrictive environment) and situational, interactional and relational factors (communication between staff and patients, staff listening to patients).

When stakeholders have different perspectives on mediating factors for adverse events, it might lead to diverse perspectives on treatment and risk management interventions needs. When such differences are not recognized and managed in a constructive way, it might become a barrier to successful recovery from mental illness and risk management (Reynolds et al., 2014). The need to extend the evolving research on involvement of psychiatric inpatients in risk assessment and management (Dickens, 2015; Lockertsen et al., 2018; Buch Gudde et al., 2015; Eidhammer et al., 2014), and to investigate their perception about risk and protective factors (Lockertsen et al., 2018) has been stressed.

\section{Contemporary challenges}

Despite the many advances within this research field, there are still contemporary challenges remaining to understand the clinical use and usefulness of structured professional risk assessments in forensic psychiatry. The prescribed procedure and intended use to inform and guide clinical interventions to prevent violence and other adverse events can be hampered in many ways.

Much research, including research on SRAIs, is not applied in forensic psychiatric practice (Fazel and Björkly, 2016). Practical challenges to the selection and implementation of SRAIs (Borum, 2003; Elbogen, 2002) have been found to affect subsequent clinical use (Vincent et al., 2016; Elbogen, 2016). However, in recent years, research has increasingly focused on how implementation of SRAIs in clinical practice can be facilitated (Guevara and Solomon, 2009; Hague et al., 2008; Perrault et al., 2012; Vincent et al., 2012a). More knowledge has been generated on the implementation of such instruments in routine clinical care (Borum, 2003; Elbogen, 2002). 
The process of selecting and the characteristics of the implementation object itself, as well as engaging stakeholders are initially important to the implementation of an SRAI (Young et al., 2006; Mullen et al., 2013). Aspects related to the users of the instrument and the importance of providing information and education on the SRAI as well as continuous support has been found to facilitate implementation (Wright and Webster, 2011). Clear communication about goals and responsibilities as well as continuous evaluation and control of fidelity to plan are needed to support clinical application (Crocker et al., 2011). The inability of SRAIs to inform clinical practice has been described as an overall barrier to widespread implementation and use (Desmarais, 2017).

There is still however a paucity of research on implementation of SRAIs in clinical settings, and the barriers and facilitators to such implementation in clinical settings are not fully understood. There have been calls for more implementation research to understand the factors that might facilitate or hinder the use of these instruments (Haque, 2016; Vojt, 2013; Desmarais, 2017; Borum, 2003; Webster, 2011).

After conducting risk assessments, presumably according to the prescribed manual and evidence-based practice recommendations (Nonstad and Webster, 2011), risk assessments then need to be documented and communicated in some way (Scurich, 2016) so that they can be used by others. There are many different techniques that can be used for the formulation of violence risk (Hart et al., 2016). However, there is no common understanding about how best to formulate and communicate risk assessments, and there is a lack of research on the effect of this step on risk prevention (Scurich, 2016; Douglas et al., 2013). Further research is needed on the extent and how different approaches to risk formulation (Hart et al., 2016), and risk communication (Scurich, 2016) inform risk management.

In a forensic psychiatric setting focused on recovery of mental illness and prevention of adverse events, the SPJI is meant to be used to inform and guide such endeavours, and often includes a description of treatment needs and suggestions in a risk management plan (Department of Health, 2007; Guy et al., 2012; Storey et al., 2015). Desmarais (2017, p. 19) concluded

...Even the most reliable and well-validated risk assessment instrument will fail to produce the desired results if not implemented with fidelity in a way that meaningfully informs practice. 
The research evidence on that SPJ risk assessments actually influence treatment and risk management in clinical settings is scarce and with that, the actual clinical usefulness of the assessment (Elbogen, 2016; Troquete et al., 2013a, 2013b; Wand and Large, 2013). The need for further research on the intended and assumed correlation between risk assessment and risk management, by adherence to risk management plans (i.e. the link between recommended and realized risk management interventions following risk assessments) has been emphasized by numerous researchers (Fazel and Björkly, 2016; Daffern, 2007; Storey et al., 2015; Singh et al., 2014a, 2014b; Sturup et al., 2013; Vojt et al., 2013).

The research evidence on what specific treatment and risk management interventions are effective in reducing different types of violent behaviours and other adverse events is insufficient (Wolf et al., 2017; Maguire et al., 2017; Elbogen, 2016; de Vogel et al., 2012). Some risk management interventions have even been found to potentially increase the risk of adverse events, such as monitoring (Coffey, 2012), seclusion and restraint (Knox and Holloman, 2012), medication, limit setting and reassurances (Maguire et al., 2017), close observation and door locking (Slemon et al., 2017) . The effectiveness of risk management interventions might also differ depending on which intervention is used for which patient (male or female), the level or risk assessed, the timing of application and how an intervention is used (Maguire et al., 2017). In addition, clear definitions of risk management interventions are lacking (Maguire et al., 2017), which can hamper research.

The narrow focus on risk has been criticized and the need to work with the patients' resources to mediate risk has been raised (de Ruiter and Nicholls, 2011). Risk assessment instruments that include strengths or protective factors have been developed in the last 15 years (Borum et al., 2006; Webster et al., 2004; de Vogel et al., 2012). It has been argued that protective factors are useful to inform risk management plans and treatment interventions to moderate risk (Arbisi, 2016). There is some indication that the complementary use of risk and protective factors could provide incremental predictive validity over the use of risk factors alone (de Vries Robbé et al., 2013). However, the lack of agreed definitions of protective factors in the research field, as well as the lack of research on the predictive validity, means that protective factors and their role in risk management are still not fully understood (Arbisi, 2016).

As mentioned above, there is also a lack of knowledge and research on patient participation in SRAs and their perceptions of mediating factors for violence (Dickens, 2015; Lockertsen et al., 2018; Buch Gudde et al., 2015; Eidhammer et al., 2014). 
In recent years, the methodological problems related to research of violence risk assessment have been in focus, such as authorship bias, poor quality of studies, inconsistent application of risk assessment tools and incomplete reporting of statistics. The need for transparency and to be aware of and account for possible biases has been highlighted (Fazel and Björkly, 2016).

The outcome measures used to evaluate the implementation and clinical use of SRAIs in clinical settings varies, which might make comparison between studies complicated (Keune et al., 2016). Examples of outcome measures can be the number of realized risk assessments (Kroppan et al., 2017; Vincent et al., 2012b), the inclusion of risk assessments in care and management plans, challenging behaviours (Crocker et al., 2011), incidents, reconvictions, readmissions (Vojt, 2013) and or changes in staff attitudes and clinical decisions (Vincent et al., 2012b). The importance of defining different outcome measures of SRAI implementation and clinical use respectively has also been stressed (Kroppan et al., 2017; Elbogen, 2016; Crocker et al., 2011). The need to develop common concepts and frameworks to evaluate the forensic psychiatric care has also been raised (Schuringa et al., 2018; Keune et al., 2016).

\section{Ethical issues}

There are several ethical issues related to the use of SRAIs in clinical settings dealing with offenders with mental disorders. It is important to be aware of such ethical dilemmas and to make efforts to mitigate the possible negative effects when conducting research as well as using SRAIs in clinical settings (Department of Health, 2007). The forensic psychiatric care itself and the juridical system behind it have been subjected to critique (Nilsson, et al., 2009), however here we will only discuss the issues related to the use of structured risk assessments. Some issue relates to the single directed view of forensic psychiatric patients as posing a threat to the public and the assumed correlation between mental illness and violence.

The use of SRAIs has been said to cause services to focus on restrictions rather than care aimed at recovery and stigmatizing an already marginalized population (Wand, 2012; Large et al., 2014), due to the focus on risk the patients pose to others (especially the static historical factors). It has been questioned as unreasonable and misguiding and adding to the staff distancing themselves from patients and reducing mentally ill people to be viewed as dangerous offenders (Carroll, 2007). A single minded view of forensic patients as violent perpetrators risks becoming a self-fulfilling prophecy, restricting them to a destructive identity and prevent them 
from recovering and finding a new identity (Coffey, 2012; Reynolds, et al., 2014).

Carroll (2007) mentions the tendency to interpret other people's behavior as a consequence of stable intrapersonal factors (such as personality traits) rather than changing situational factors. Such bias in forensic care and SRA could add to the stigmatization of forensic psychiatric patients and a focus on restrain rather than treatment due to the perceptions of the problems being difficult to change. Carroll (2007) argues that a SRA that incorporate both stable and dynamic and protective factor could instead be used to mitigate such bias and stigmatization.

People can be violent for any number of reasons, being mentally ill can certainly be one reason. Mentally ill people can however also be violent for the same reasons as everybody else (Carroll, 2007, Peay, 2009) Whether the mental illness adds an additional risk can depend on the type and severity of symptoms, ongoing treatment interventions, socio- economic circumstances and other contextual aspects and so forth. Most mentally ill people are most often not violent. Mentally ill people are furthermore often more exposed to violence by people in the community without mental illness, than the other way around (Peay, 2009; Towl, 2005). The perceived inability of mentally ill offenders to control themselves adds to the view of mentally ill as unpredictable and dangerous (Peay, 2009). Research however suggests mentally ill people are often actively managing their risk of acting out using a wide range of strategies (Olsson et al., 2015). Using these facts to balance the restricted view on mentally ill offenders and the potential risk they pose to others, can mitigate stigmatization of already disadvantaged and vulnerable individuals. Including diverse types of risk, such as victimization, in the SRAI and dynamic and protective factors (Carroll, 2007; Carroll 2008) could facilitate such balance.

A risk assessment within forensic psychiatric care can be used in clinical and juridical considerations of balancing the needs, interest and liberties of the individual forensic psychiatric patient with the need of keeping the community/public safe from potential harm (Konrad, 2016). Towl (2005) however question this distinction and points out that mentally ill offender are an inherent part of the public, and that they don't lose their citizenship just because they are incarcerated for a while. "Many members of the public are offenders and all offenders are part of the public" (p 92).

Forensic psychiatric patients can be concerned about the risk others pose to them as well as the risk they might pose to others (Pulsford, et al., 2013). 
Douglas, et al., 2017) stress that "Competing values in risk assessments does create a potential ethical problem" ( $\mathrm{p}$ 135) if the patients interests are "unjustifiably" overrun by other interest. However even when a risk assessment results in further detention and restrain (to protect other people/the public) it might still be in the individuals best interest as well. The patient's needs and rights might at times clash with the need to prevent that person from harming others. Ultimately, it is a question of what risks we are willing to take and how we perceive the risks and benefits of different choices and the risk of false-positives (unwarranted restriction of patients' rights) and false-negatives (patients reoffend/act violently) (Douglas et al., 2017). Large and Nielssen (2017) suggest any lenience of such restrictions to patients can only be motivated if the risk assessment methods have proved to be effective in actually reducing violence and do not entail an intolerable cost to this already disadvantaged population.

Some argue it's not necessarily the structured risk assessment itself that pose the ethical problem, but how it's being used. Nilsson et al. (2009) suggest these assessments can have a purpose in guiding and evaluating clinical treatment strategies and research about such issues, but recommend refraining from using them to make assumptions about recidivism and to make juridical decisions. Another problem arises when an assessment of a patient's potential risk of violence in the future, are used as if it is a fact, i. e. when a statement of probability becomes a prediction (Towl, 2005).

Insufficient and or inconsistent involvement of forensic psychiatric patients in the risk assessments conducted as part of their care risks further marginalization of this population and to prevent their development to be/become as autonomous and responsible as possible. Other ethical issues arise when patient are encouraged to participate and issues related to how this is done. Konrad (2016) emphasize the need to inform forensic psychiatric patients about the purpose of the risk assessment, how it might be used, to whom it is communicated, and the potential consequences of participating and not participating in the risk assessment. Towl (2005) also stress the importance of being mindful of the power imbalance between the patient and the clinician, especially when doing risk assessments in clinical settings (due to the potential consequences). The care providers further need to provide a climate were contradictory opinions can be openly expressed, and were contradictory views are not immediately considered to be a sign of lack of insight and resistance to care (Reynolds, et al., 2014).

The clinical relevance and ethicality of conducting risk assessments, even SPJ risk assessments, has been questioned since the risk factors specified in these instruments are not causal to violence and that the management of such factors does hence not necessarily influence recidivism (Nilsson, 
et al., 2009). The methodological and ethical problems of translating statistically derived risk factors related to groups of populations to assess the risk of an individual have been raised (Cooke and Michie, 2009). The SPJ approach, as exemplified in the HCR-20 V3, does however encourage the assessor not only to assess the presence of risk factors but also the relevance of each factor to the individual (Judges, et al., 2016; Douglas et al., 2013).

Conducting structured risk assessments within forensic psychiatric care is necessary and mandatory and the SPJ approach is part of clinical guideline recommendation (Department of Health, 2007; NICE, 2007; Risk Management Authority, 2006) as it seem to be the best available option at the moment (Douglas, et al., 2017). No risk assessment, however well conducted, will ever be able to predict the future with any certainty. All risk assessments are subjected to some level of uncertainty (Grisso \& Vincent, 2005). It's important to be aware of and open about this, and not to be persuaded to answer the risks more definitely than warranted. As Grisso \& Vincent (2005) point out, it's important to acknowledge what we don't know and what we cannot do, to promote further research and knowledge development, a sound ethical approach were the method is not being used the wrong way, as well as an inspire a credibility to the thing we do claim to know, and do say.

The clinical utility and research evidence for the effect of such assessments (thru the risk management plan and interventions) to prevent future adverse events are still insufficient (Douglas, et al., 2017). There are also serious potential ethical complications with the use of SRAI in these settings and also about how these assessments are being used by different stakeholders that need to be considered.

\section{Summary}

Despite the many advances within this research field, there are still challenges remaining to understand the clinical use and usefulness of structured risk assessments in forensic psychiatry. The need for more research has been raised in relation to

- Barriers and facilitators to the implementation of SRAIs in clinical settings (Haque, 2016; Vojt, 2013; Desmarais, 2017; Borum, 2003; Webster, 2011);

- How best to formulate and communicate risk assessments to inform risk management (Hart et al., 2016; Scurich, 2016);

- How and to what extent the SPJ risk assessment and risk management plan actually influence clinical care and risk management in clinical settings by informing and guiding the planning of such interventions (Troquete et al., 2013a, 2013b; Wand and Large, 2013; 
Fazel and Björkly, 2016; Daffern, 2007; Storey et al., 2015; Singh et al., 2014a, 2014b; Sturup et al., 2013; Vojt et al., 2013);

- What specific treatment and risk management interventions are effective in reducing different types of violent behaviour and other adverse events (Wolf et al., 2017; Maguire et al., 2017; de Vogel et al., 2012);

- Clear definitions of risk management interventions (Maguire et al., 2017);

- Definitions and the predictive validity of protective factors (Arbisi, 2016); and

- Patient participation in risk assessments and their perceptions of mediating factors for violence (Dickens, 2015; Lockertsen et al., 2018; Buch Gudde et al., 2015; Eidhammer et al., 2014).

Figure 1 provides a simplistic summary overview of the main steps and actions described in the intended use of SRAIs in forensic psychiatric settings and the gaps in research evidence. It is derived from previous research and aims to show what is being done, or should or needs to be done, for SRAIs to have the intended effect of violence prevention. As described above, ARAIs only cover steps 1 and 2, whereas SPJIs cover steps 1 to 4 . As unstructured clinical assessments (UCJs) are still common and other types of influencing factors, such as patients' own initiatives, can influence recovery and adverse events, these are also included in the figure. The outcome in terms of adverse events and recovery is thought to be considered in revised structured risk assessments.

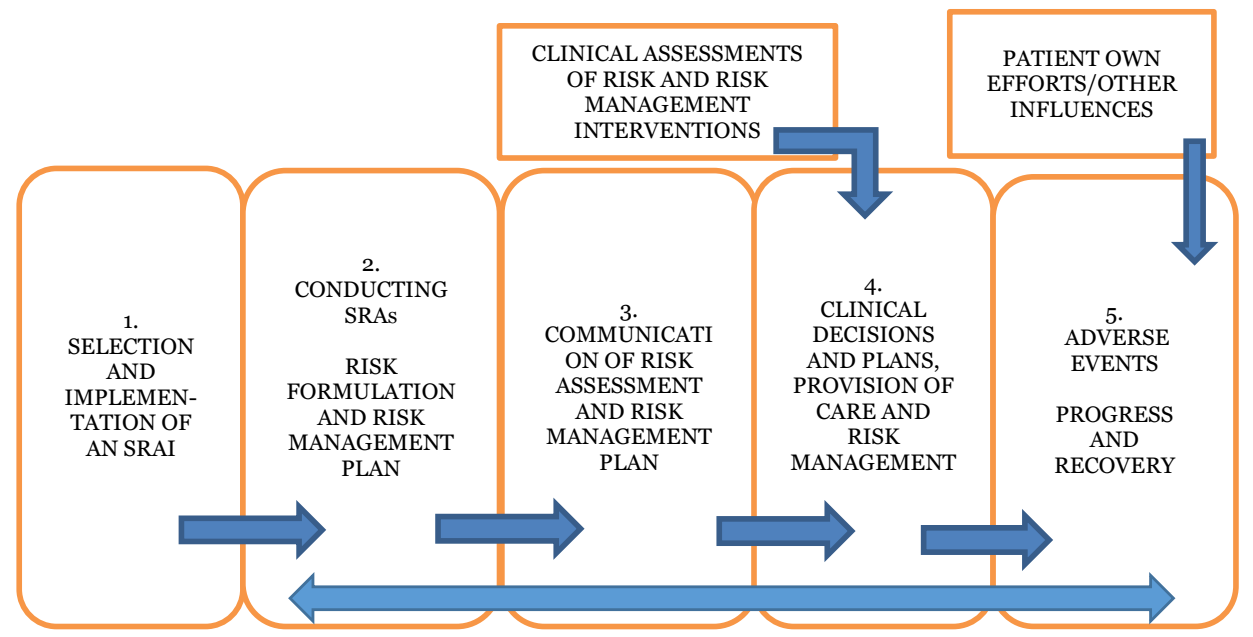

Figure 1. Steps in the intended use of SRAIs in forensic psychiatric settings. 


\section{Rationale}

The thesis comprises four studies investigating issues related to the use of SRAIs in clinical settings, addressing some important knowledge gaps identified in previous research. These gaps needed to be investigated to improve understanding of the use, effect and value of SRAIs in clinical settings.

- How to ascertain implementation and use of structured risk assessment instruments in forensic settings and how to ensure that the assessment has a clinical use and value;

- The clinical use of structured professional judgement risk assessment instruments in terms of guiding treatment and risk management plans, as well as clinical fidelity to these plans;

- Risk-increasing and risk-decreasing factors for violence according to patients' perceptions. 


\section{THEORETICAL FRAMEWORK}

\section{Theories and frameworks}

The studies applied some theories and frameworks for structuring, analysing and interpreting the data and results. In study 1 , the Consolidated Framework for Implementation Research (CFIR) was used (Damschroder et al., 2009). Study 2 applied the Diffusion of Innovation Theory (Rogers, 1983) and the Self-Determination Theory (Ryan and Deci, 2000). They are briefly described here.

\section{Consolidated Framework for Implementation Research (CFIR)}

Review data in study 1 were analysed using CFIR, an implementation determinant framework developed by Damschroder et al. (2009). Determinant frameworks point to specific determinants, often referred to as barriers and facilitators (or enablers), to implementation success. CFIR includes theories and research evidence of implementation determinants within a framework that can be applied in multiple settings.

CFIR consists of five different types of implementation determinants (called domains in CFIR), i.e. different factors that influence implementation processes and outcomes. Characteristics of the implementation object (i.e. the practice being implemented, in this case an SRAI) include aspects such as intervention source, strength of evidence, evidence of effect, relative advantage, adaptability, trial ability, complexity, design and packaging and cost. Characteristics of the users of the practice being implemented (i.e. staff in psychiatric, correctional, or community inpatient care) include knowledge and beliefs about the intervention, self-efficacy, individual stages of change, commitment to the organization and other personnel attributes. Characteristics of the inner setting where implementation occurs include structural characteristics, networks and communications, culture, implementation climate and organizational commitment to implementation. Characteristics of the outer setting of the implementation include organization knowledge of patient needs and resources, organizational networks, competition between organizations and external policies and incentives. Process determinants (i.e. activities undertaken to influence the implementation) include planning, engaging and formally appointing different stakeholders, executing, and reflecting and evaluating. 


\section{Diffusion of Innovation Theory}

Diffusion of Innovation Theory (Rogers, 1983) is widely used in organizational and communication research but is also recognized as an important theory in implementation science. Rogers' so-called innovation attributes are incorporated in the CFIR characteristics of the implementation object and are not described in more detail here. Another component of Rogers's theory is the classification of individuals based on their willingness to try out an innovation. The theory describes five different adopter categories based on how early individuals adopt innovations. Even though user characteristics and their motivation for change are included in CFIR, reference to Rogers is suggested for a more in-depth analysis. This theory was used to understand the differences in staff perceptions and approaches to the implementation of a new SPJI in study 2.

The five adopted categories described by Rogers (1983) are the following: (1) innovators, who are the first to try the innovation, venturesome and interested in new ideas, willing to take risks, very little, if anything, needs to be done to appeal to this population; (2) early adopters are opinion leaders, enjoy leadership roles, embrace change opportunities, already aware of the need for change, comfortable adopting new ideas, require how-to manuals and information sheets on implementation, do not need information to convince them to change; (3) early majority individuals are rarely leaders, adopt new ideas before the average person, typically need to see evidence that the innovation works before they are willing to adopt it; (4) late majority individuals are sceptical of change, will only adopt an innovation after it has been tried by the majority, need information on how many other people have tried the innovation and have adopted it successfully; and (5) laggards are bound by tradition and very conservative, very sceptical of change and are the hardest group to bring on board, need statistics, fear appeals and pressure from people in the other adopter groups.

\section{Self-Determination Theory}

Aspects of Self-Determination Theory were used in study 2 to interpret data and understand the staff's different approaches and perceptions of the implementation process and the clinical usefulness of a structured assessment instrument.

Self-Determination Theory (Deci and Ryan, 2000) describes behaviours in terms of relative autonomy, i.e. self-determination, reflecting the extent to which a person endorses what he or she is doing. Three broad types of motivation are described: (1) intrinsic motivation (performed for its inherent satisfaction, e.g. for the fun, interest or challenge it offers, a natural, inherent drive to seek out challenges and new possibilities); (2) ex- 
trinsic motivation (i.e. integrated, identified, introjected and externally regulated behaviour such as demands and rewards); and (3) amotivation (no intention to perform a behaviour). A considerable body of research exists that shows that more intrinsically motivated behaviours are more stable, performed with greater care and quality, and accompanied by more positive experiences (Ryan and Deci, 2000). 


\section{AIMS}

The overarching aim of this thesis was to investigate the implementation and use of structured risk assessment instruments to prevent violence and other adverse events and to improve understanding of the factors that influence such events among forensic psychiatric patients.

The thesis addresses the following research questions:

1. In what way does the implementation process of a specific structured risk assessment instrument affect integration and use in a clinical setting?

This research question was addressed in study 1 by investigating the research evidence on implementation determinants (barriers/facilitators) for structured risk assessments in psychiatric, correctional and community inpatient settings. It was also addressed in study 2 by investigating the implementation determinants as perceived by the users/staff for a specific SRAI in a forensic care unit.

2. In what way does performing a structured professional judgement risk assessment affect the documented care and risk management in a clinical setting?

This research question was addressed in study 2 by investigating how/if the implementation of START (Short Term Assessment of Risk and Treatability) actually affected staff understanding and/or decisions and their provision of care and risk management (according to staff perceptions). It was also addressed in study 3 by investigating the risk management interventions that were planned (in structured risk assessments and/or unstructured clinical assessments) and realized in a forensic psychiatric care facility, according to an analysis of patient records.

3. What do forensic psychiatric patients perceive to be risk-increasing and risk-decreasing factors for violence, and how can their own experiences add to understanding of the causes and prevention of violence risk.

This research question was addressed in study 4 by investigating what patients themselves perceived to be mediating circumstances for their violence. 


\section{METHODS}

This section outlines the study setting, study populations and methods used to collect and analyse the data in the thesis studies. Ethical considerations related to the methodology are also discussed. Figure 2 presents an overview of the steps in the intended use of SRAIs in forensic psychiatric settings and the aspects investigated in the thesis studies.

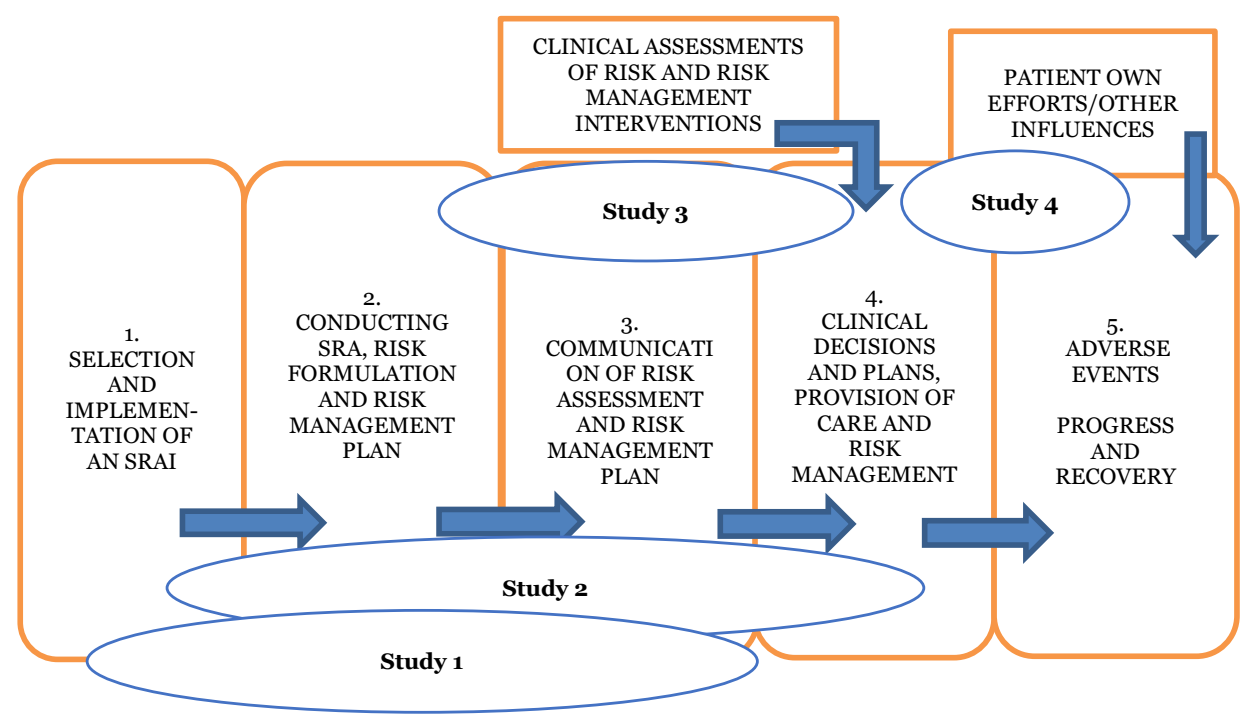

Figure 2. Steps in the intended use of SRAIs in forensic psychiatric settings.

The thesis studies are different in character and investigate different aspects of the intended use of SRAIs, as well as other potential factors influencing care and risk management interventions and adverse events. Diverse methods for data gathering and analysis were also used (Table 1).

Table 1: Overview of studies and methodology

\begin{tabular}{|l|l|l|l|l|}
\hline & Study 1 & Study 2 & Study 3 & Study 4 \\
\hline $\begin{array}{l}\text { Study } \\
\text { design }\end{array}$ & $\begin{array}{l}\text { Systematic review, } \\
\text { deductive search and } \\
\text { analysis procedure }\end{array}$ & $\begin{array}{l}\text { Qualitative inductive } \\
\text { approach }\end{array}$ & $\begin{array}{l}\text { Qualitative and } \\
\text { quantitative, mixed } \\
\text { method, inductive and } \\
\text { deductive }\end{array}$ & $\begin{array}{l}\text { Qualitative inductive } \\
\text { approach }\end{array}$ \\
\hline $\begin{array}{l}\text { Study } \\
\text { populati } \\
\text { on and } \\
\text { setting }\end{array}$ & $\begin{array}{l}\text { 11 studies from forensic, } \\
\text { psychiatric or correctional } \\
\text { inpatient settings }\end{array}$ & $\begin{array}{l}\text { 18 clinical staff from a } \\
\text { forensic psychiatric } \\
\text { clinic }\end{array}$ & $\begin{array}{l}\text { patiens records } \\
\text { patich }\end{array}$ & $\begin{array}{l}\text { 13 forensic } \\
\text { psychiatric patients }\end{array}$ \\
\hline
\end{tabular}




\begin{tabular}{|c|c|c|c|c|}
\hline $\begin{array}{l}\text { Data } \\
\text { collectio } \\
\text { n }\end{array}$ & $\begin{array}{l}\text { Search of databases } \\
\text { Medline/PubMed, } \\
\text { CINAHL, and PsychINFO }\end{array}$ & $\begin{array}{l}\text { Three semi-structured } \\
\text { focus group interviews }\end{array}$ & $\begin{array}{l}\text { Review of patient } \\
\text { records using a coding } \\
\text { scheme }\end{array}$ & $\begin{array}{l}\text { Semi-structured } \\
\text { individual interviews } \\
\text { with patients }\end{array}$ \\
\hline $\begin{array}{l}\text { Data } \\
\text { analysis } \\
\text { procedu } \\
\text { re }\end{array}$ & $\begin{array}{l}\text { The Consolidated } \\
\text { Framework for } \\
\text { Implementation Research } \\
\text { (CFIR) (Damschroder et } \\
\text { al., 2009); quality } \\
\text { assessment of } \\
\text { trustworthiness (Patton, } \\
\text { 2002) }\end{array}$ & $\begin{array}{l}\text { Conventional qualitative } \\
\text { content analysis (Hsieh } \\
\text { and Shannon, 2005) }\end{array}$ & $\begin{array}{l}\text { Directed content } \\
\text { analysis, applying } \\
\text { deductive categories } \\
\text { (Mayring, 2000; Hsieh } \\
\text { and Shannon, 2005) }\end{array}$ & $\begin{array}{l}\text { Qualitative content } \\
\text { analysis (Graneheim } \\
\text { and Lundman, } \\
\text { 2004) }\end{array}$ \\
\hline $\begin{array}{l}\text { Stage in } \\
\text { the } \\
\text { SRAI } \\
\text { process } \\
\text { (Figure } \\
\text { 2) }\end{array}$ & $\begin{array}{l}\text { Focus on stages } 1,2 \text { and } 3 \\
\text { (stage } 5 \text { is mentioned in } \\
\text { terms of implementation } \\
\text { outcome) }\end{array}$ & $\begin{array}{l}\text { Aspects of stages } 1,2,3 \\
\text { and } 4 \text { are investigated }\end{array}$ & $\begin{array}{l}\text { Aspects of stages } 2,3 \\
\text { and } 4 \text { are investigated }\end{array}$ & $\begin{array}{l}\text { Aspects of stages } 4 \\
\text { and } 5 \text { are } \\
\text { investigated }\end{array}$ \\
\hline
\end{tabular}

\section{Study setting}

The first study was a systematic review and included several clinical settings, such as forensic psychiatric care, psychiatric care, juvenile services, juvenile probation services and correctional probation service from several different countries. The other three studies in the thesis were undertaken at one of Sweden's six major forensic psychiatric regional clinics with a particular responsibility to conduct research related to the forensic psychiatric populations, including SPJIs and their clinical use.

The clinic provides care for about 70 patients predominantly sentenced by the courts to forensic care after having committed a crime due to major mental illness. The patients are predominantly diagnosed with psychosis, personality disorders, mental retardation/developmental dysfunctions and neuropsychiatric disorders. The clinic has seven wards with security levels ranging from 1 (high), 2 (medium) and 3 (low). Forensic care in Sweden is governed by the Social Council and is publicly funded.

\section{Study 1}

Study 1 aimed to synthesize experiences and previous research of SRAI implementation in clinical settings. A systematic review is a suitable method to synthesize previous research in an objective and systematic way (SBU, 2017). The systematic search and review of previous research was qualitative deductive in terms of using predefined inclusion and exclusion criteria and a predefined framework to elicit implementation determinants. However, a quantitative count of the determinants in the analysis process was also included.

Study 1 included 11 published articles in English describing the implementation of an SRAI to assess and manage risk of violence to others. Three of the studies were undertaken in the United States, three in Cana- 
da, three in the United Kingdom, one in Australia, and one in Norway. Seven of the 11 papers were published in 2010 or later. Eight of the studies were conducted in psychiatric care; one study was located in juvenile services, one in juvenile probation services, and one in a correctional probation service. The SRAIs in the 11 studies ranged from well-established and validated instruments to locally developed and less well-researched instruments. In one study, determinants were elicited and described on the basis of author experiences, three combined author experiences with file reviews, one combined author experiences with feedback from staff, and two combined author experiences with both feedback from staff and file reviews. Three studies used a combination of file reviews and feedback from staff and one study relied solely on feedback from staff to gather information.

The articles described and analysed the implementation of an SRAI to assess and prevent risk of violence in psychiatric, correctional, or community inpatient settings. A systematic literature search was conducted in March 2014 using a multi-search service function at Linkoping University library in databases relevant to the research field of risk assessments: Medline/PubMed, CINAHL, and PsychINFO. The Cochrane database was searched separately. The search was filtered to include scientifically relevant articles but allowed a wide range of publications types (academic journals, reviews, theses/dissertations, conference materials, and reports). A MeSH term search identified a number of different synonyms relating to risk assessment, the clinical setting, and implementation. Duplicates were eliminated, resulting in 1590 unique articles.

The first author read the abstracts of articles with titles and summaries within the targeted research field of risk assessment in the specified clinical contexts. Articles of potential interest were identified from the titles and abstracts. The articles were read in full by the first author who consulted with the other three authors to discuss borderline cases. Inspection of the reference lists of these articles produced another two articles of potential interest. Eleven articles were included in the review.

In the absence of shared definitions and frameworks to evaluate implementation in the field of structured risk assessment instruments in clinical settings (Schuringa et al., 2018; Keune et al., 2016), borrowing frameworks such as CFIR from the field of implementation science can be alternative (Haque, 2016). CFIR in turn synthesize several implementation theories and previous research from different research fields within the health care services (Damschroder et al., 2009). CFIR (Damschroder et al., 2009) was used to identify and categorize hindering and enabling factors related to implementation determinants. CFIR distinguishes between five types of implementation determinants: (1) characteristics of the implementation object (i.e. the SRAI); (2) characteristics of the users of the SRAI (i.e. staff in psychiatric, correctional, or community inpatient care); 
(3) characteristics of the inner setting; (4); characteristics of the outer setting; and (5) process (i.e. activities undertaken to influence the implementation).

A systematic review should include a quality assessment of the reviewed studies (SBU, 2017). The quality of the studies was assessed in terms of four aspects of trustworthiness, as suggested by Patton (2002): credibility, confirmability, transferability, and dependability. Credibility refers to the internal validity of the research study and how well the findings and interpretation of the data address the research questions and how congruent findings are with reality. Confirmability relates to efforts to prevent the researcher's preconceptions affecting the results instead of the informants' responses. Dependability refers to the consistency of data and the possibility of repeating the study and findings. Transferability is concerned with external validity and generalizability of the findings to other situations or settings. The authors assessed these four aspects of research trustworthiness, rating aspects as unsatisfactory, fair, or good depending on the extent to which the studies fulfilled the criteria. All authors independently assessed the articles before the assessments were compared and discussed. Consensus was then reached regarding a conclusive quality assessment.

\section{Study 2}

A pilot project aimed at implementing an SPJI to provide an evidence base guide for the unstructured clinical risk assessments in two wards was conducted at the clinic. As part of the evaluation of the project, staff perceptions of the instrument, the implementation process and the clinical usefulness, were investigated.

Several state-of-the-art risk assessment instruments, such as the HCR-20 (Webster et al., 1997) were in use at the study site for long-term risk assessments, whereas short-term risk assessments on the wards relied on clinical judgements. The clinic management and research unit recognized a need to implement an evidence-based routine for assessment of patients' risk of adverse events in the wards. The use of structured decision support was also requested by the nursing staff and the manager on the wards involved in the project. The research unit evaluated different shortterm risk assessment instruments, from which START was selected. The START (Webster et al., 2004) manual was translated into Swedish by the head of the clinic research unit and distributed to staff at the clinic with formal consent from the authors of START.

Before implementation of START, the care team and staff on the two wards were trained in its use for 2 days and informed of the rationale of 
the project, new routines and the clinical evidence suggesting the need for change. To facilitate the transition of education to actual assessment experience, staff conducted the first START assessments of the patients on the wards under supervision by the first author. The initial supervision was part of the training and an implementation support measure. Staff expressed a continuous need for such support during assessments. The care team psychologist, highly trained and experienced in risk SPJ assessment instruments, was therefore assigned to act as method advisor.

The START assessments were piloted from mid-2010 (planning and start of information meetings and training) to early 2013 (evaluation of the implementation) in two wards at the clinic providing care for 24 patients with predominantly chronic psychosis, low functioning and neuropsychiatric disorders. The START assessments conducted from autumn 2011 to the end of 2012, approximately 14 months, were part of the study. The assessments were made by a multi-professional care team every 3 months to assess risk for the patients on the wards. Staff were asked to fill in background information and past risk before meetings.

Staff were given the opportunity to fill in an evaluation form after attending each assessment meeting. The purpose was to continuously gather information in a structured way about staff perceptions, and to identify and quickly respond to potential problems they experienced during the project. The evaluation form was used as an implementation support and for continuous follow-up, rather than as a means of evaluating the implementation itself. The evaluation form was based on a translation of Doyle and Brown, Short Term Assessment of Risk and Treatability Pilot Questionnaire, from 2005. Staff completed the evaluation form anonymously. Several adjustments to project routines were made based on comments on the evaluation forms.

In study 2, the population consisted of 18 staff from the care team and ward staff in the two wards at the clinic responsible for conducting the START assessments during the pilot implementation. Staff (45) were approached by mail and asked about participation. The mail included information about the research project, terms of participation and interview guide themes. Participation was voluntary and 23 responded positively. Five informants agreed to participate but were unable to participate at the time of the interviews because of sick leave or having to prioritize other clinical responsibilities that day as a result of staff shortages on the wards. Consenting informants received written information in connection with the interview about the research project and participation and were able to ask questions. All participating professions in the project were represented in the interviews, such as a ward administrator, a nurse, a psychiatrist, a psychologist, a social worker, an occupational therapist and ward/nursing staff. 
Three focus group interviews were conducted. The focus group interviews lasted between 63 and 80 minutes. The first author, with previous experience in group interviews, was moderator for all three interviews to improve reliability (Hylander, 2001). No observer moderator was present. Considering the differences in the formal and clinical mandate, and to avoid some individuals dictating the discussions (Hylander, 2001), ward staff and other professions were interviewed separately. The focus group participants had worked together and knew each other. Some of the care team staff (including the psychiatrist, psychologist and social worker) had previous experience with conducting SRAs using a manual, but most participants (nurses, ward staff and occupational therapist) had not.

Data in study 2 were collected by means of three audio-recorded focus group interviews, a method commonly used to gather user-related information within less researched areas and to assess the implementation of new procedures (Hylander, 2001; Wibeck, 2010). They are effective in capturing the perspectives of a group of people with a shared experience. Focus groups are considered less leading than surveys or individual interviews because the participants are allowed to direct the discussion more towards what they think is important, and they are allowed to use their own words to describe their experiences. The researcher's influence is therefore reduced. The participants may also bring up issues that the researcher had not previously considered. A focus group also has the benefit of participants reminding each other about shared experiences, and the discussion can make participants more open (Hylander, 2001).

Other means of data collection were considered, but defining appropriate questions for a survey might have been presumptuous given the paucity of previous research. Staff conducted, used and made sense of the assessment in collaboration with each other, thus making a group interview more similar to the clinical reality. It was considered important to include as many of the participating staff as possible to get as many different perspectives as possible, again making focus group interviews suitable for data collection (Hylander, 2001). Focus group data can be gathered to investigate the content and group processes; addressing the aim of this study, the primary interest was the content.

Staff conducted, used and made sense of the assessment in collaboration with each other, thus making a group interview similar to clinical reality. It was considered important to include as many of the participating staff as possible to get as many different perspectives as possible, again making focus group interviews suitable for data collection (Hylander, 2001). Focus group data can be gathered to investigate the content and group processes; addressing the aim of this study, the primary interest was the content. 
A semi-structured interview guide was used specifying three different themes related to the aim and previous research about possible moderating aspects: the implementation process, conducting risk assessments using the SRAI procedure and the clinical use of these assessments. Each theme was introduced to the focus group by the moderator as open-ended questions and participant's responses then determined the content of the following discussions.

Conventional content analysis is appropriate for studies with a qualitative inductive approach to address a less well-researched phenomenon with text data gathered by means of open-ended interview questions (Hsieh and Shannon, 2005). The transcribed focus group interview data in study 2 was analysed using conventional qualitative content analysis based on the manifest content of the participants' responses, allowing categories to emerge from the data inductively (Hsieh and Shannon, 2005). The transcriptions were read repeatedly and meaning-bearing units related to the aim were marked. Preliminary categories were analysed according to their internal homogeneity and were compared to ensure their external heterogeneity. The analysis process followed the original data, constantly comparing the relationship between statements and the labelling and definitions of the category to which they were sorted. The first author sorted statements to a suggested label and category and three senior researchers ( $\mathrm{PB}, \mathrm{PB}$ and $\mathrm{PN}$ ) examined the definitions and content of the sorted statements. Any discrepancies were discussed until agreement was reached (Hsieh and Shannon, 2005; Patton, 2002).

\section{Study 3}

An inductive approach was used in study 3 in terms of constructing the coding scheme to review patient records. The review of patient records was conducted using directed content analysis, applying deductive categories. A directed approach is suitable to validate or extend a previously described theory or phenomenon. The previously described phenomena are drawn upon and used to guide and focus the research questions and variables of interest. Hence, study 3 applied a mixed method approach in terms of qualitatively extracting and analysing the type of risk management interventions documented in the records and quantitatively presenting the data in frequencies of each category. The approach was deductive in the use of predefined descriptions of risk management interventions and inductive by allowing new categories to emerge from the data. Statistical calculations can be a way of strengthening findings. Establishing correlations were however beyond the scope of study 3 and further statistical calculations were not deemed necessary. The previous study investigating the realization of recommended risk management interventions also reported frequencies in terms of percent, allowing for comparisons (Singh 
et al., 2014b). The findings in study 3 were however reported in a way that allows for future statistical calculations and comparisons with a data integration approach (Desmarais, 2017).

The 14 patient records reviewed were conscripted from the two wards of the pilot implementation project, housing 24 patients. All patients were informed about the study at morning meetings in the ward and asked about agreement to have their patient records reviewed. Both written and oral information was then provided to the patients individually. Fifteen patients agreed to have their records reviewed, but one consenting patient died before the data collection started and was therefore excluded from the study.

Fourteen patient records covering 526 months were reviewed. Even though the participants were recruited when staying in the two wards, some were transferred to other wards at the clinic, other forensic psychiatric clinics, open forensic psychiatric care outside the clinic, and some were discharged. This resulted in differences in the time reviewed for different patient records, ranging from 14 to 42 months. Most of the study population were men $(71 \%)$ and $29 \%$ were female; the mean age was 31 years and the mean time in forensic care was 2.5 years. Most of the study population had two to five different diagnoses, the most common main diagnoses were schizophrenia, psychosis, neuropsychiatric disorders and developmental dysfunction. Half of the study population had two to five offences when sentenced to forensic care, the most common index offences being arson, physical assault and murder/manslaughter.

Directed content analysis, applying so-called deductive categories, was used to review the patient records. A directed approach is suitable to validate or extend a previously described theory or phenomenon. The previously described phenomena are drawn upon and used to guide and focus the research questions and variables of interest. Data can be meaningfully reported in terms of frequencies and incidences of the defined categories (Mayring, 2000; Hsieh and Shannon, 2005). Counting frequencies and reporting results in percentages was deemed suitable and sufficient to provide data on occurrences and allowing for comparisons to address the research questions.

Definitions and concepts were drawn from previous definitions of risk management interventions, summarized in a coding scheme, applied directly to code the initial data, and then revised based on the findings (division and addition of main categories and subcategories) throughout the analysis process. The preliminary coding scheme was piloted on two patient records by the first author. The two pilot records were selected after the first author had read all the records and noted a wide variety of interventions in the selected samples. Triangulation of inter-rater reliability was carried out on the two patient records. 
Notes were discussed by the first author, PSB, PB and PN. Based on findings from the pilot analysis, some additions were made to the coding scheme. Revisions were done to reduce overlapping headings, and some headings and subsections were added. When all records had been analysed, the last version of the coding scheme was discussed by all authors, before being used by the first author to re-analyse all the records a second time, from December 2009 to June 2013 (3.5 years). The type of risk management intervention was registered as (1) planned but not realized, (2) planned and realized or (3) realized. Unstructured clinical assessments were broadly defined as any documentation from weekly round meetings, care plan meetings (every 6 months), nursing care plan followups and daily notes made by staff on the ward.

SRAs with a structured professional judgement approach (SPJ assessments) included documentation of HCR-20 (Webster et al., 1997), START (Webster et al., 2004), SVR-20 (Sexual Violence Risk -20; Boer et al., 1997), SRP (Stalking Risk Profile; MacKenzie et al., 2009) and/or RSVP (The Risk of Sexual Violence Protocol; Hart et al., 2003) assessments.

Data in study 3 were coded according to the constructed coding scheme identifying eight main categories: monitoring (observation, visitations and control of substance use); supervision (limitations of movement, social interaction, communication and access to resources); assessment (psychological, occupational, psychosocial and SRA); treatment (medication, psychotherapy, psychoeducation, nursing care, occupational activities); victim protection (interventions to inform and support potential victims); acute coercion (100\% supervision, coerced medication, seclusion, and/or physical restraints); security level (level of security, number of staff, number of patients); police interventions (police interventions to gather information and/or deal with an identified risk).

\section{Study 4}

A qualitative inductive approach was considered appropriate to investigate patient perceptions. Previous studies investigating patient perceptions have predominantly used predefined surveys and rating sheets (Pulsford, et al, 2013; Dickens 2013; Chaplin, et al, 2006; Duxbury, 2005; Gillig, et al., 1998). Such instruments restrict the opportunity for patients to use their own words and may not capture the full range of patient perspectives. It has been emphasized that forensic patients might not use the same terms as those used in survey instruments, pointing to the relevance of taking a more inductive approach to exploring the patient perspective (Dixon, 2012). For these reasons individual interviews were chosen to investigate patients own perspectives allowing them to use their own 
words to define violence and mitigating factors that reduce or increase this risk.

The 13 participants for study 4 were recruited from the regional forensic psychiatric clinic. Patients in the two high-security wards were not included because the time they spent in forensic care was often short, causing a lack of information and making assessment of inclusion and exclusion criteria precarious. A total of 87 patients ( 55 from 4 inpatient wards and 32 patients from open forensic care) were initially considered for inclusion in the study; 52 were excluded when considering the inclusion and exclusion criteria, leaving 35 patients allegeable for inclusion in the study. Twelve patients declined to participate, 13 agreed and 10 patients (in open forensic care) could not be reached.

Patients were assessed by their psychiatrist with regard to the inclusion criteria (ability to understand and communicate in Swedish; sufficient psychiatric stability; ability to make an informed decision about participation) and exclusion criteria (inability to make an informed decision about participation; risk of participation causing the patient severe stress/distress, or risk of an adverse event; previous or ongoing intervention contact with the first author). A meeting with patients eligible for inclusion was arranged by nursing staff, who also attended the meeting. The first author introduced herself and the patients were informed verbally about the study and asked about participation. Consenting patients were then read the written information about the study and also the consent. A date for the interview was booked.

The study population consisted of $85 \%$ males and $15 \%$ females with a mean age of 41 years. Most had more than one index offence, the most common offences being physical assault (77\%), unlawful verbal threats (46\%) and arson (23\%). The most common main psychiatric diagnoses were schizophrenia (38\%), schizoaffective disorder (15\%) and developmental disorders (15\%). Most had more than one psychiatric diagnosis, often related to substance abuse (54\%), personality disorder/syndrome (30\%) and cognitive dysfunction (23\%).

The interviews took place on the patient's ward, and the safety procedures on the ward were followed, for example, wearing an alarm. Before the interviews, the first author checked the current state of the patients with nursing staff on the wards to make sure it was a good day to conduct the interview.

A semi-structured interview guide was constructed with a few open-ended questions following the patient's own experience of violent acts. The definition of violence was deliberately kept open at the beginning of the interview because violence can be defined in different ways by different patients and the purpose of the study was to allow patients to describe their 
experiences and conclusions in their own words. The definition included violence directly or indirectly aimed at the patient themselves or another human being, intended or unintentional, physical use of violence, but also intended or planned use of violence and threats of violence. Participating patients were asked about aspects and circumstances they perceived to increase (risk factors) or decrease their use of violence (protective factors or risk management interventions).

The interview guide had open-ended questions to allow patients to use their own words to describe their experiences. The participants' descriptions of their experiences and perceptions were followed up with further questions to explore more details and summarizing questions to ensure the interviewer understood what was being said. Suggestive and leading responses were avoided, but more probing questions were used when participants struggled to understand the open-ended questions. The use of more probing questions was especially scrutinized by the other authors in the transcribed interviews and if a probing question was answered only with the participant agreeing or repeating it without adding some aspect in their own words, it was removed from the analysis. Thirteen interviews with patients lasting for 10 to 110 minutes were completed. The audiorecorded data were transcribed by a professional transcriber and double checked by the first author.

Qualitative content analysis with an inductive approach was used in study 4, as described by Graneheim and Lundman (2004), where the analysis was based on the manifest content of participants' responses. The transcribed interviews were read through several times to obtain a sense of the whole. Then meaning-bearing units related to the research questions were highlighted, extracted and condensed, still keeping to the participants' own words. The condensed meaning units were then abstracted and labelled with a code. The codes were compared, and differences and similarities were considered when sorting the codes into categories.

During the stages of the analysis, the original transcriptions were read again and considered in the discussions to facilitate a clear link between participants' statements and subsequent labelling. The first author and a senior researcher did the extractions of meaning-bearing units, condensation, labelling and sorting of codes and categories separately and then compared and discussed differences until consensus was reached. All authors were involved in differentiating the sub- and main categories.

\section{Methodological and ethical considerations}

Several methodological and ethical factors were considered in the planning and completion of the thesis studies. Ethical approval for studies 2, 3 
and 4 was given by the Regional Ethical Review Board in Linkoping (Dnr 2011/109-31).

The moderator and first author (SL) is a clinical psychologist in two other wards at the clinic and was also part of the implementation project as a research administrator. This might have made it difficult for staff and patients to speak openly (Hylander, 2001).

The first author specifically asked for both positive and negative opinions during the focus group interviews, was mindful to avoid dominating the discussion and tried to create an open discussion climate. The moderator's familiarity with the organization and ongoing implementation project increases the understanding of the informants' perspectives and statements, on the one hand, but also increases the risk of being influenced by preconceived notions. The moderator was aware of this risk and made every effort during the interviews not to assume to understand unspoken or implied references, instead encouraging informants to describe what they meant and what they were referring to. Longer conversations from the interviews are reported in the Results section when possible, rather than just single comments from participants, mainly to illustrate the basis for the categories and the role of the moderator and thereby improving face validity.

To facilitate patient participation without feeling pressured, it was emphasized both verbally and in the written information that the care would not be affected in any way if they agreed or declined to participate and no compensation was offered if they agreed to participate. An assessment of the patient's ability to understand the informed consent and what participating in the interview could mean, but also their ability to express their wishes, was conducted by their physician before they were approached.

The risk of participants experiencing distress in the interview situation was considered when planning the study and by the inclusion and exclusion criteria. The participants were also asked at the end of the interview how they had perceived the interview and given the opportunity to talk about their feelings. They were also asked whether they were in need of support by nursing staff after the interview. No participant expressed such a need. The time of the interview was arranged in cooperation with staff to ensure the patients' contact persons were in place and prepared to offer assistance. Participants were especially informed about the opportunity to take a break or end the interview at any point if they perceived it to be too distressing (and in two cases they did) and were given the option of continuing at another time if they wanted (they declined, expressing they had said what they wanted). 


\section{RESULTS}

\section{Implementation determinants for structured risk assessment instruments in clinical settings (study 1)}

The SRAIs in the 11 articles reviewed in study 1 ranged from wellestablished and validated instruments to locally developed and less wellresearched instruments. In one study, determinants were elicited and described on the basis of author experiences, three combined author experiences with file reviews, one combined author experiences with feedback from staff, and two combined author experiences with both feedback from staff and file reviews. Three studies used a combination of file reviews and feedback from staff, and one study relied solely on feedback from staff to gather information.

The quality of the articles in terms of research trustworthiness, as defined by Patton (2002), differed considerably. The transferability in terms of the richness of the description of the background, SRAI, and study context was mostly rated as fair. Dependability, as evaluated by the audit trail, was rated as fair or unsatisfactory. Many studies provided information regarding data sources but failed to describe by whom and how the data were analysed and on what basis conclusions were drawn. Credibility, as evaluated by the description and evidence of the findings, was mostly found to be fair. Most studies had a clear description of the findings related to the research question and to previous research. A few studies also used quotes to demonstrate close links with the data. With one exception, confirmability (evaluated in terms of reflexivity and triangulation), was deemed unsatisfactory.

Implementation determinants identified in the 11 studies are reported according to the domain and subcategories of the Damschroder et al. (2009) framework CFIR (Table 2). The domain "outer setting" and several subcategories of other domains within the CFIR were not linked to implementation in any of the studies reviewed. The reviewed studies mentioned between 11 and 17 different implementation determinants, except for one study that only mentioned 6 . 


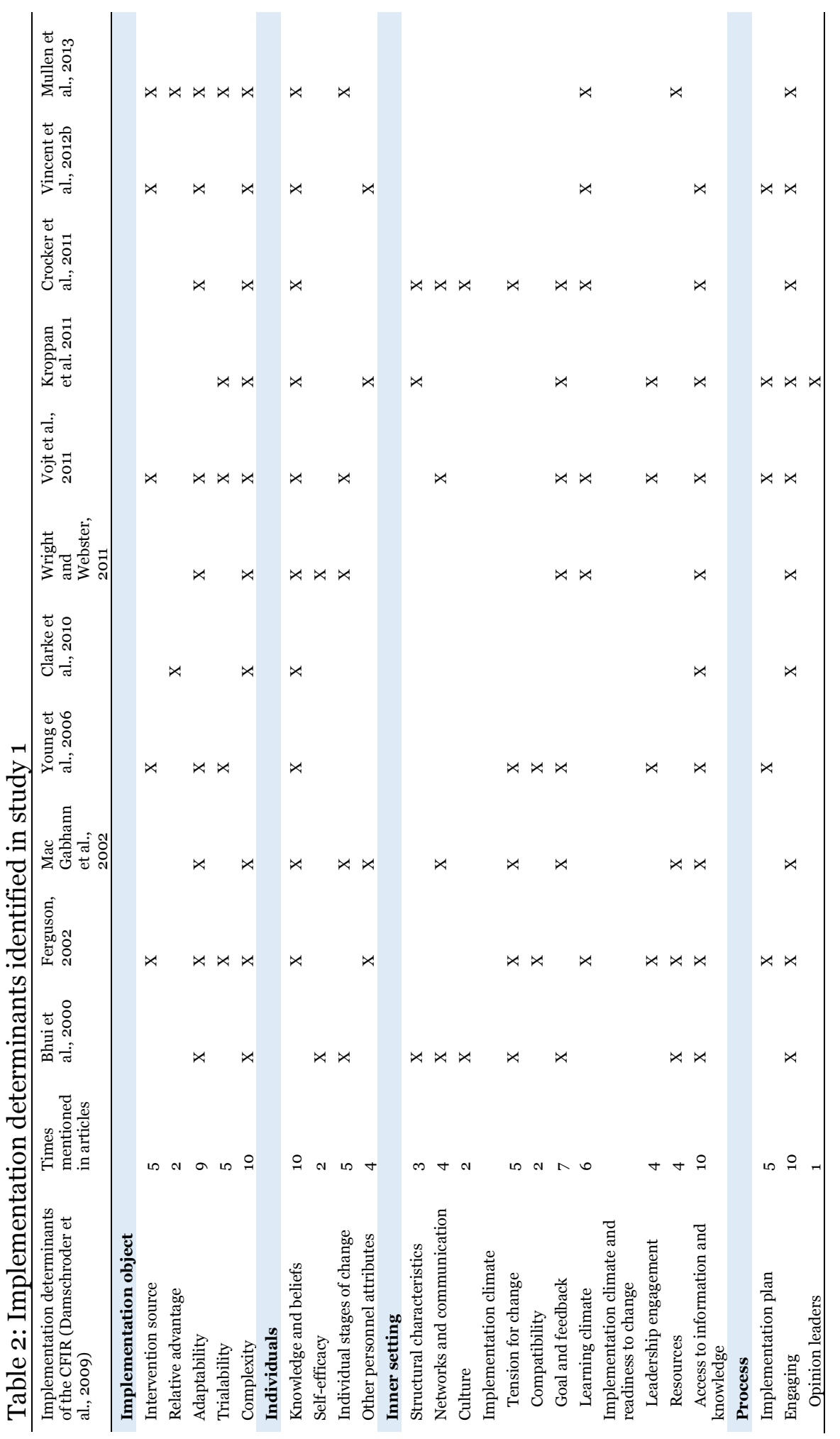




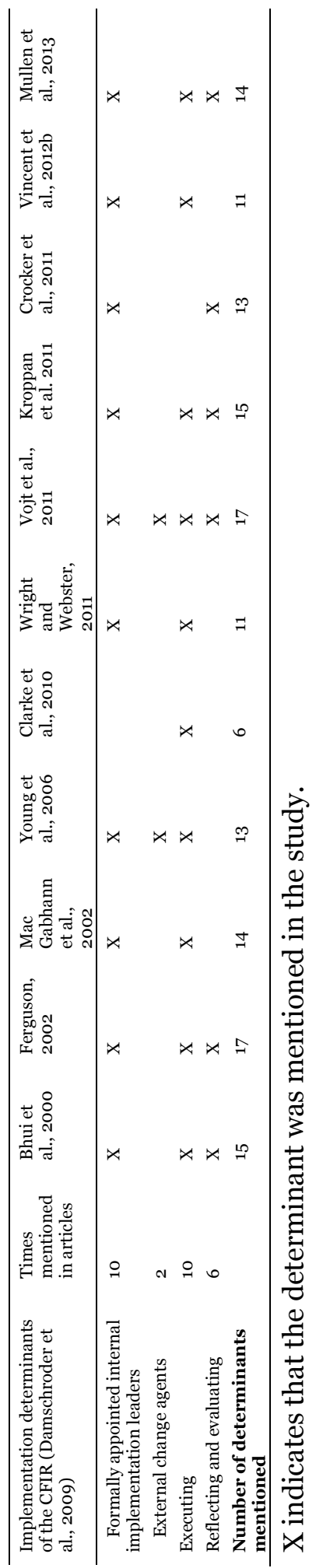


The most commonly mentioned implementation aspects of the characteristics of the implementation object were adaptability (the possibility of adapting the SRAI to local needs and practice, adjusting routines that staff found problematic) and complexity (in terms of the SRAI requiring a significant change in practice, the use of the SRAI being time consuming and difficult, creating increased workload and changes in decisionmaking routines and priorities).

The most frequently mentioned implementation determinants of the characteristics of users was knowledge and beliefs about the intervention, i.e. the SRAI users' beliefs, perceptions, concerns, and opinions about the SRAI and its implementation. Negative and lack of previous experience of participation in an implementation project were associated with negative expectations and found to be a barrier to implementation.

Implementation aspects related to the characteristics of the inner setting were goals and feedback (specification of the responsibilities, communication of goals and tasks, as well as the performance indicators and time limits for implementation), learning climate (the leaders' willingness to acknowledge the need to involve staff as a "knowledgeable participant" in the implementation process and provide sufficient time and space for staff members to take an active part in the implementation) and access to information and knowledge (easy access to digestible information, education, training, and continuous support over time to users concerning the SRAI as well as the implementation process). Adapting such training to fit the local legal framework and users, and providing such information and training early in the implementation process, were emphasized as important.

The most commonly mentioned implementation determinants related to the main domain process were engaging (involving different stakeholders to facilitate the implementation). All studies emphasized the importance of ensuring the engagement of users early in the process and then making sure that this engagement continued throughout the implementation. Use of formally appointed implementation leaders (engaging opinion leaders with certain qualities and qualifications, such as the ability to command respect and authority, but also having a commitment to change) was also emphasized. Executing (various means of monitoring the implementation process to ensure the fidelity of the planned course of action) was also frequently mentioned in relation to the process domain. Monitoring could be in the form of reports/protocols, information technology control systems, conducting a research study, repeated training, and pilot evaluation.

A wide variety of implementation determinants were mentioned in the review indicating that the implementation of an SRAI in any clinical set- 
tings is a highly complex and multifaceted endeavour. Several different stakeholders and many different aspects at different system levels in the organization need to be considered.

\section{Staff perceptions of facilitators and barriers to the use of a short-term risk assessment instrument in forensic psychiatry (study 2)}

In the pilot implementation project at a forensic psychiatric clinic in Östergötland, Sweden, a total of 48 structured risk assessments, using the START instrument, were conducted during a 14-month evaluation period, involving a total of 27 unique patients. One to three START assessments were completed for each patient with a mean time between the first and second START assessment of 6 months. The planned interval of 3 months was not achieved because new patients were admitted to the ward and others were transferred to other wards or to open forensic care. Some assessment meetings were also cancelled and rescheduled because of shortage of staff, usually due to sick leave, vacation periods or having to prioritize other work such as dealing with emergencies. The average number of staff present at the START meetings was six.

Staff perceptions of barriers and facilitators that affected the clinical use of START were investigated with focus group interviews including 18 staff The findings were classified into three main categories, following the content analysis process: factors that were associated with characteristics of the implementation object (i.e. START), the context and the users (see revised Table 3 without extracts from quotes; for full table, see article study 2). Barriers were negative aspects (perceived disadvantages, challenges, difficulties, etc.) and facilitators were positive aspects (perceived advantages, utility, benefits, etc.) regarding the use of START as part of clinical practice.

Table 3 Overview of the findings in study 2

\begin{tabular}{|c|c|c|}
\hline Category & Facilitating & Barrier \\
\hline \multicolumn{3}{|l|}{ Implementation object } \\
\hline $\begin{array}{l}\text { Comprehensiveness and } \\
\text { complexity }\end{array}$ & Inclusion of protective factors & $\begin{array}{l}\text { Unreasonably time consuming } \\
\text { and extensive }\end{array}$ \\
\hline Participant requirements & $\begin{array}{l}\text { A diverse group of professionals; } \\
\text { having enough staff with training } \\
\text { and good patient knowledge }\end{array}$ & $\begin{array}{l}\text { Ratings different due to } \\
\text { composition of participants }\end{array}$ \\
\hline $\begin{array}{l}\text { Drifting from the clinical } \\
\text { perspective }\end{array}$ & & $\begin{array}{l}\text { Tendency to focus too much on } \\
\text { history and risk }\end{array}$ \\
\hline $\begin{array}{l}\text { Diverse reasons for assessed } \\
\text { change }\end{array}$ & & $\begin{array}{l}\text { Different staff evaluating the } \\
\text { same information differently; }\end{array}$ \\
\hline
\end{tabular}




\begin{tabular}{|c|c|c|}
\hline & & $\begin{array}{l}\text { concern about failing to consider } \\
\text { changes }\end{array}$ \\
\hline $\begin{array}{l}\text { Increased knowledge and } \\
\text { understanding }\end{array}$ & $\begin{array}{l}\text { Provided a learning opportunity } \\
\text { about risk and protective factors }\end{array}$ & \\
\hline $\begin{array}{l}\text { Increased unity, clarity and } \\
\text { improved communication }\end{array}$ & $\begin{array}{l}\text { Increased unity and consensus of } \\
\text { defining and communicating risk } \\
\text { and care needs; provided a } \\
\text { standard routine for } \\
\text { documentation, improving } \\
\text { communication of knowledge }\end{array}$ & \\
\hline $\begin{array}{l}\text { Clinical use when planning daily } \\
\text { activities }\end{array}$ & $\begin{array}{l}\text { Used clinically to make decisions } \\
\text { about use of privileges and } \\
\text { specific activities; possible } \\
\text { implicit use }\end{array}$ & $\begin{array}{l}\text { Perceived limited and unclear } \\
\text { clinical use }\end{array}$ \\
\hline \multicolumn{3}{|l|}{ Context } \\
\hline $\begin{array}{l}\text { Provision of information and } \\
\text { training }\end{array}$ & $\begin{array}{l}\text { Good and sufficient information } \\
\text { and training provided initially }\end{array}$ & $\begin{array}{l}\text { Lack of information and training } \\
\text { to new staff; lack of booster } \\
\text { training; uncertainty about } \\
\text { clinical use of START }\end{array}$ \\
\hline Support and supervision & $\begin{array}{l}\text { Expert advisor part of care team, } \\
\text { ability to consult SL; support of } \\
\text { mid-level manager }\end{array}$ & $\begin{array}{l}\text { Lack of everyday support at ward } \\
\text { level }\end{array}$ \\
\hline $\begin{array}{l}\text { Competing responsibilities and } \\
\text { workload }\end{array}$ & & $\begin{array}{l}\text { Difficult to keep up with other } \\
\text { responsibilities and increased } \\
\text { strain; staff turnover and other } \\
\text { organizational changes made it } \\
\text { difficult to allocate necessary } \\
\text { manpower }\end{array}$ \\
\hline Access to assessments & & $\begin{array}{l}\text { Difficult and time consuming to } \\
\text { find assessments in records; lack } \\
\text { of unified documentation }\end{array}$ \\
\hline \multicolumn{3}{|l|}{ Users } \\
\hline Expectations and preconceptions & $\begin{array}{l}\text { Some staff perceived a need for a } \\
\text { structured routine to make daily } \\
\text { risk assessments }\end{array}$ & $\begin{array}{l}\text { Staff perceived a need for and } \\
\text { expected a more concise risk } \\
\text { assessment method }\end{array}$ \\
\hline Attitudes & Some staff positive to change & $\begin{array}{l}\text { Perceiving START to be just } \\
\text { another assignment adding to an } \\
\text { already heavy workload; negative } \\
\text { attitudes spread and were } \\
\text { discouraging }\end{array}$ \\
\hline Motivation and incentives & $\begin{array}{l}\text { Mandatory, no choice; feeling } \\
\text { chosen and responsible; taking } \\
\text { the START assessments seriously }\end{array}$ & \\
\hline $\begin{array}{l}\text { Continued reliance on clinical } \\
\text { experiences }\end{array}$ & $\begin{array}{l}\text { A structured risk assessment } \\
\text { potentially helpful in complex } \\
\text { cases }\end{array}$ & $\begin{array}{l}\text { Continued reliance on clinical } \\
\text { judgement; finding it hard to } \\
\text { change old habits }\end{array}$ \\
\hline Individual characteristics & $\begin{array}{l}\text { Characteristics such as } \\
\text { tenaciousness, ability to find } \\
\text { meaning, supporting colleagues } \\
\text { and solving problems }\end{array}$ & \\
\hline
\end{tabular}

Several categories were found to be related to the characteristics of the SRAI, i.e. the implementation object. Including protective factors and a short-term clinical perspective in the risk assessment as opposed to only risk and historical aspects was perceived as a benefit of the SRAI and to be a facilitator. 
The START assessments improved staff knowledge about risk and protective factors, made staff more informed about and provided a more nuanced comprehension of the patient, and improved staff ability to understand the content of other SRAIs. The assessments also increased the consensus within the care team and provided a standard routine for structured documentation, which improved communication.

The START assessments were used clinically in some cases to make decisions about use of privileges and planning daily activities, especially when there was some disagreement among staff, and used in court and to inform staff outside the care team. However, staff also perceived the START to be too time consuming, extensive and strenuous to use and that it was a challenge to fully incorporate protective factors in the assessments despite their perceived importance.

A few facilitating aspects related to the context were found, such as the provision of sufficient and adequate training on the START method, encouragement provided by the ward manager and having a method expert advisor at meetings. However, staff perceived a need for follow-up training and additional continuous supervision.

Conducting the START assessments also took time from other responsibilities and strained staff resources, and there were problems allocating the necessary time and manpower to deal with staff turnover and other organizational changes. Staff also found it difficult to find and understand the assessments in the patient records because of inconsistent documentation and not having enough time to retrieve and read them to make quick daily decisions.

Facilitating implementation determinants related to the characteristics of the users of the SRAIs was a perceived need of a structured risk assessment. Thus some staff found the START assessment useful other not in complex cases. Staff completed the assessments because it was mandatory, they felt chosen and responsible for the evaluation of the SPJI and took it seriously because these assessments often have a substantial impact on patients' lives. Characteristics such as tenaciousness, ability to find meaning in their work, willingness to support each other and ability to solve problems acted as facilitators. Some staff perceived a lack of clinical usefulness of SPJI and most continued to rely mainly on their own clinical experience to make daily clinical decisions. They were confident in their own ability to accurately and sufficiently assess and manage risk that way. 


\section{Adherence to planned risk management interventions according to patient records (study 3 )}

To investigate the planned and realized risk management interventions, 14 patient records covering a total of 526 months (3.5 year period from December 2009 to June 2013) were reviewed. Some of the patients were committed to forensic care after the start of the study period, others were transferred to other forensic psychiatric clinics during the study period, transferred to open forensic psychiatric care outside the clinic, and some were discharged. This resulted in differences in the amounts of time reviewed for different patient records, ranging from 14 to 42 months. The participants had one to four START assessments (37 registered in total), 11 had one HCR-20 assessment, two had an RSVP assessment, two an SVR-20 assessment and one an SRP assessment.

In this study, $76 \%$ of the risk management interventions planned in UCJs were realized. Of the risk management interventions planned in the SPJ assessments, $83 \%$ were realized. Most of the interventions planned in SPJ assessments (78\%) were also planned in UCJ assessments, and hence overlapped. Some risk management interventions were documented frequently (supervision in terms of limitation of movement outside the ward, treatment such as nursing care on the ward, medical assessment and medical treatment); others were seldom documented (victim protection and different kinds of acute coercion). For several types of risk management, most of the interventions realized ( $62 \%$ for all interventions) were not actually documented as planned.

A total of 2638 risk management interventions were recorded. Three different types of monitoring interventions were noted: observation, visitation and control of substance use. Monitoring interventions were documented as realized 187 times. Overall, $45 \%$ of the UCJ planned and 53\% of the SPJ planned monitoring interventions were realized. Twenty-eight percent of the SPJ and UCJ planned monitoring interventions overlapped. Seventy percent of all realized monitoring interventions were not planned at all.

Five different types of supervision interventions were documented: limitation of movement, social interaction, electronic communication and access to resources and belongings. Supervision interventions were documented as realized 536 times. The UCJ planned supervision interventions were realized in $70 \%$ of cases, and in $90 \%$ of the SPJ planned cases. There was 90\% overlap between SPJ and UCJ planned supervision interventions; $41 \%$ of the realized supervision interventions were not planned. 
Four types of assessment interventions were documented: psychological, occupational, psychosocial and structured risk assessments. Assessment interventions were documented as realized 105 times; $80 \%$ of the UCJ planned and $67 \%$ of the SPJ planned assessment interventions were realized. Eighty-three percent of the SPJ planned assessment interventions were also planned in UCJ assessments; $44 \%$ of the realized interventions were not planned at all.

Seven different types of treatment interventions were documented: medication, psychotherapy, psychoeducation, environmental treatment/ nursing care, medical assessment meetings with psychiatrist, occupational activities and other not specified. Treatment interventions were noted as realized 1672 times. Overall, 85\% of the UCJ planned and 95\% of the SPJ planned treatment interventions were realized. Ninety-six percent of the SPJ planned treatment interventions were also planned in UCJ assessments. Sixty-eight percent of the realized treatment interventions were not planned.

Half of the UCJ planned and 80\% of the SPJ planned victim protection interventions were realized according to the documentation. Eighty percent of the SPJ planned interventions were also planned in UCJ assessments. Sixty-four percent of the realized interventions were not planned. Victim protection interventions were seldom documented. Acute coercion interventions were not frequently used and only planned in UCJ assessments. The planned interventions were realized in half of the cases, but most often the realized interventions were not planned at all.

Most of the planned changes in security level and/or changes in the form of care were realized, 75\% in UCJ assessments and 100\% in SPJ assessments. All SPJ planned interventions were also planned in UCJ assessments. Twenty-two percent of all realized interventions were not planned. All UCJ and SPJ planned police interventions were documented as realized. All SPJ planned interventions were also planned in UCJ assessments. Sixty-three percent of all realized police interventions were not planned.

According to what was documented, most planned risk management interventions are realized in both SRAs and unstructured clinical assessments. The large overlap of planned interventions between the two types of assessments suggests a unified view of treatment and risk management needs among nursing staff, care teams and external risk assessors. However, most of the realized interventions were not planned, in either structured or clinical assessments. This means a large part of the care provided is not following a predetermined plan, potentially making it open to subjective clinical assessment and decision making. 


\section{Forensic patients' perceptions of risk-increasing and risk-decreasing factors for violence (study 4)}

This study sought to investigate the perspectives of forensic psychiatric patients on factors that influence the risk of violence, based on individual semi-structured interviews. The findings suggest that there are many different types of factors that influence the risk of violence, according to patient's perspectives. These factors relate to themselves and external influences, social and relational aspects, and situational factors. There is considerable overlap between the risk-increasing and risk-decreasing factors that the patients perceived to be important and the factors included in commonly used and clinically relevant SPJIs in forensic psychiatri care (e.g. HCR-20 V3, START and SAPROF [Structured Assessment of Protective Factors for Violence Risk] Ramesh et al., 2018; Judges, et al., 2016; Doyle and Leonard, 2016).

Risk factors related to the external context such as exposure to traumatic events, influence of violent settings and stressful living conditions, lack of social integration and support, insufficient psychiatric care and problems with treatment planning and delivery, are all part of HCR-2O V3 and START. Risk factors related to the inner individual circumstances, such as mental health problems, substance use, pro-violent attitudes and values, lack of insight, difficult feelings and unstable/unmanageable emotionalstate, lack of behavioural control, insufficient cognitive abilities/functioning, not considering the consequences and insufficient coping, are also part of HCR-20 V3 and START.

However, a few exceptions were found. Participants expressed that being ignored and treated badly by care providers was a risk factor for violence, something that is not listed in HCR-20 V3 or START. When talking about the content of psychiatric care, several participants mentioned different problems related to medication as risk increasing. This is not mentioned as a specific risk factor in HCR-20 V3 or START. However, not adhering to prescribed medication is mentioned as a problem with treatment and supervision response in HCR-20 V3 and within treatability and medication adherence in START.

Participants identified many different risk-decreasing factors, both protective factors and risk management factors, most of which were consistent with SRAIs using an SPJ approach, e.g. SAPROF and START. These instruments include protective factors mentioned by the participants related to the internal characteristics and prerequisites of the individual, such as having the will to get help and to make a change, insight, empathic ability, considering negative consequences, prosocial attitudes 
and behaviour, ability of self-control and emotional stability. Protective factors in terms of external contextual prerequisites, such as living conditions and social integration and prosocial support, also overlapped with factors listed in SAPROF or START. Risk management factors, such as internal strategies and aspirations in terms of having alternative coping strategies, and in terms of external interventions such as a functioning a health care system and compulsory psychiatric care, also overlapped with factors listen in SAPROF or START.

However, a few risk-decreasing factors identified by participants are not listed in either SAPROF or START. The ability to consider negative consequences requires empathy and cognitive functioning, which are listed in SAPROF and START and described by patients. Actually experiencing negative consequences, as opposed to only imagining them, seemed to be a separate factor according to the patients, but are not listed in SAPROF or START. Staff treatment of patients is not mentioned in either SAPROF or START, but is described as important by the participants in this study as a means to reduce violence risk. The importance of the provision of care and professional support are mentioned in SAPROF and START, but not how they are implemented. Being able to find and be themselves again and having a sense of who they are were mentioned by participants as risk reducing but they not listed in START or SAPROF. For some, the mental illness itself could be risk reducing by making them avoid other people to engage in conflict and fights or not having the energy to act on provocations and anger. Mental illness is not mentioned in any SRAI as a specific risk-decreasing factor, but it is included in the overall prescribed considerations in both SAPROF and START; both instruments include recognition that psychiatric symptoms can act as a protective factor.

\section{Summary of thesis findings}

Forensic patients' risk of future violence needs to be assessed in some way. Previous research and the findings in this thesis suggest that the use of risk assessment instruments with a structured professional judgement approach can aid clinicians in this endeavour. However, the instrument needs to be introduced with fidelity to an implementation plan and clinically used with fidelity to evidence-based standard recommendations, the prescribed procedures and suggested risk management plans. Ethical considerations and including the perspectives of the individual patients also need to be incorporated in the assessment and risk management plan to be able to accomplish this in a legally sound and humane way.

There are a wide variety of determinants for the implementation and clinical use of SRAIs. These can relate to the characteristics of the implemen- 
tation object, the characteristics of users/individuals, the inner setting/context and process as found in studies 1 and 2. Hence, applying a multifactorial approach to the implementation of SRAIs, accounting for many different barriers and facilitators at different system levels seem warranted. Limiting the required need for change of existing routines and hence the strain on the organization can facilitate implementation. Keeping the complexity of the instrument to a minimum and reducing the need for resource allocation seems especially important.

Most of the planned risk management interventions, both in structured and unstructured risk assessments, were realized according to patient records in study 3, indicating support for the clinical usefulness of SRAIs. Most of the interventions planned in SPJ assessments were also planned in UCJ assessments, indicating a large overlap between these two approaches previously described having different relevance. For several types of risk management, most of the realized interventions were not actually documented as planned, indicating that most care and risk management interventions are based on subjectivity.

The participants proved to be capable to identify and communicate many different types of factors that influence the risk of violence. These factors relate to themselves and external influences, social and relational aspects, and situational factors. There is a considerable overlap between the riskincreasing and risk-decreasing factors that the patients perceived to be important and factors included in commonly used SRAIs (e.g.HCR-20 V3, START and SAPROF) and found in previous research. 


\section{DISCUSSION}

The study findings are discussed in this chapter. It is structured according to the aims and research questions. The discussion also addresses methodological issues of the thesis studies.

\section{Discussion of findings}

The overarching aim of this thesis was to investigate the implementation and use of SRAIs to prevent violence and other adverse events and to improve understanding of the factors that influence such events among forensic psychiatric patients.

\section{Determinants influencing implementation and clinical use of SRAIs in forensic psychiatric settings}

The literature search yielded only 11 articles from different forensic settings, which confirms that there is still a lack of research on SRAI implementation in different clinical settings although the need for such research has been stressed for some time (Borum, 2003; Webster, 2011). The methodological quality of the reviewed studies varied, but was insufficient overall. These finding points to the importance of more stringent research on SRAI implementation to obtain more solid evidence of the factors that impede or enable this implementation.

The findings in studies 1 and 2 identified implementation determinants at different system levels, relating both to the instrument (i.e. the implementation object), users of the SRAIs, the inner organizational setting and the implementation process itself. These findings suggest a need for a flexible multifactorial approach to the implementation of SRAIs to target many different barriers and facilitators at different system levels. No previous systematic review of implementation of SRAIs in clinical settings could be found in a literary search, making it difficult to compare findings with previous research. However, the findings are consistent with the broader implementation science literature, which emphasizes the importance of multi-level determinants (Damschroder et al., 2009).

There was an overlap between what previous studies identified as important implementation determinants for SRAIs, as seen in study 1, and what staff perceived to be important based on study 2. Some of the over- 
lapping determinants related to the strain on the organization and the users in the implementation of the new SRAI. The complexity of the SRAI, the resources required and amount of change needed to adapt to new routines were found to be relevant in studies 1 and 2 (Haque, 2016; Ferguson, 2002). Again, these findings are in line with the broader implementation science literature (Damschroder et al., 2009).

Study 2 evaluated the introduction of a comprehensive risk assessment instrument (START) in routine care. The inclusion of a variety of both risk and protective factors and the consideration of different types of risk made the START assessment more comprehensive, complex and time consuming. This posed a major barrier for implementation and clinical use of the START instrument. Using a comprehensive SRAI might be clinically relevant to address the variety of situations encountered in forensic care. Comprehensive instruments however often require more resources and support to be manageable for staff and the organization and might also take resources from other important tasks (Vincent et al., 2012b; Wright and Webster, 2011).

Staff in study 2 perceived a benefit and relevance of including protective and short-term dynamic clinical factors in the risk assessment to inform about care and risk management interventions and to prevent a narrow focus on long-term historical risk factors. This perspective was suggested as necessary in previous research, as well as the aim of including such dynamic protective factors in SRAIs (Arbisi, 2016). The single focus on risk has also been said to influence a focus on restrictions and cause stigmatization of forensic patients (de Ruiter and Nicholls, 2011). Including protective and dynamic factors could facilitate a more nuanced view of patients and direct focus to recovery. Due to human tendency for anchoring bias, i.e. an initial judgement is unlikely to change despite evidence to the contrary (Towl, 2005), a diverse descriptions of forensic psychiatric patients risks and abilities might need to be incorporated already in the initial risk assessment. This could be an explanation to the problems with integrating protective factors in the structured risk assessments found in study 4 . Despite staff's efforts to include protective factors, their risk assessments still tended to focus more on historical risk. Sometimes the implementation and use of an SRAI requires not only a change in knowledge, routines, responsibilities, and mandate but also a change in inveterate preconceptions, habits and culture. This suggests more implementation strategies and resources might be needed to facilitate the inclusion of protective factors in SRAs conducted in clinical settings.

How staff perceived and adjusted to change seemed to be affected by their confidence in their ability to deliver on new routines but also by a perceived loss of professional discretion, which can be a barrier to SRAI implementation (Kroppan et al., 2011; Ferguson, 2002). A number of user 
characteristics seem to have affected the staff's approaches to change, their attitudes, motivation, knowledge and skills, which also indicate differences in the need for information, training, support and motivation to engage in new routines (Rogers, 1983; Deci and Ryan, 2000). Such differences need to be identified and addressed to facilitate implementation and use of the SRAI.

Staff perceived problems accessing the assessments in records as a barrier to clinical use in study 2. They found it difficult to find and understand the assessments in the patient records because of inconsistent documentation and not having enough time to retrieve and read them to make quick daily decisions. Limited time to gather relevant information to make daily clinical assessments and decisions, have been mentioned as a barrier to the clinical use of SRAIs (Elbogen, 2016). Staff suggested specific interventions to make assessments quickly and easily accessible to facilitated implementation and use. They also suggested having a printed, short version of the START assessment and lists of possible risk management interventions for a specific risk situation available on the ward. UCJs are often easier and quicker to assess than SRAs documented in patient data records. With the time pressure and limited staff resources often characterizing the everyday clinical work at a forensic clinic, the use of UCJs might seem to be the only feasible option. Even the most accurate and informative risk assessment will likely not be read or used to inform daily clinical decisions if the clinicians cannot access it easily and quickly. Having systematic and clear documentation of the risk formulation easily accessible on the ward could improve clinical use.

Staff perceived difficulties in translating the risk assessments and the risk management plans into clinical situations they encountered. More concrete and specific suggestions on possible care and risk management interventions for specific risk situations could help facilitate clinical use of SRAs. Despite the inclusion of a risk management plan in SPJ risk assessments and the guidelines outlined in the manual of these instruments, there seems to be a need for further support to facilitate the translation of these risk assessments and management plans in clinical everyday care (Wright and Webster, 2011; Webster et al., 2006; Crocker et al., 2011), which indicates just how difficult this step can be. The clinicians might need more training on and have access to specific guidelines and concrete examples of how the risk assessment could be used in specific situations to transfer the document into action.

The definitions and evaluations of the outcome of implementation in clinical settings vary, as well as what constitutes a successful or failed implementation, making comparisons between studies difficult (Schuringa et al., 2018; Keune et al., 2016; Grimshaw et al., 2006; Cohn, 2002). This is particularly true for "people serving" services with multiple goals (Cohn, 
2002, p. 6). Several of the principles of the START were achieved (Webster et al., 2010), such as more structure and subsequent documentation and communication of clinical decisions, improved knowledge about risk and protective factors and skill in conducting SRAs. Subjectivity in assessments was perceived to be limited, and the possibility of scrutiny and evaluation of clinical practice were improved. The START assessments were also sometimes used clinically to make decisions about granting leave and activities. However, staff continued to rely mainly on their previous UCJ approach and, after the pilot implementation study, the use of the START instrument was terminated at the clinic. Despite their many benefits, the START assessments were perceived as too complex and time consuming to be conducted by care teams every 3 months, and efforts needed to compensate for the remaining barriers would have been substantial (e.g. continuous follow-up training and support for all staff at the clinic) to manage the implementation and use of the START over time.

The clinical utility of a SRAI can be considered in terms of a cost benefit perspective. The costs of an SPJI implementation need to be compared with the gains to make sense and to facilitate motivation and adherence to the new SRAI routines (perceived cost versus benefit is mentioned as an implementation determinant in CFIR). The cost in terms of time might outweigh the potential benefits (in terms of more efficient risk assessment and management), especially in clinical settings with high caseloads and low base rates of violence with their populations (Carroll 2008). The cost in, terms of the SRAI being more time consuming, have also been found to be counterbalanced by providing a more comprehensive risk assessment (more dynamic, applicable, clear, structured, detailed, specific) (Judges, et al., 2016). Staff and management at the clinic found the use of START on the wards to be too much work compared with the perceived benefits. The choice of which SRAI to implement need not only consider the judicial setting and clinical population but also relevant types of risk and the time perspectives involved. The SRAI may need to incorporate several different types of risk and mediating factors to address commonly encountered situations and hence be clinically relevant. However, a comprehensive risk assessment instrument might be so time consuming and resource demanding that it becomes a barrier to clinical use, no matter how clinically relevant.

Giving staff a say about the selection or development of the SRAI can create a sense of ownership that facilitates implementation as suggested in study 1. Staff was not involved in the selection of START in study 2 and, despite some perceived need for an SRAI to structure their everyday decisions, what they wanted and expected was a less extensive SRAI that could be used in a matter of minutes. Including staff in the selection of an SRAI to use on the wards could have resulted in a less comprehensive 
SRAI that was more manageable for the staff and required fewer resources, and a different outcome of the implementation project.

Some staff in study 2 claimed to continue to rely on their clinical judgement. Others were uncertain about the extent that the START assessment influenced their clinical practice and suggested an implicit influence that they were unable to perceive. Previous research has also found indications of a clinical use of an implemented SRAI, despite statements from staff claiming to continue with business as usual (Clarke et al., 2010). The use of SRAI has been found to make the documentation more systematic and structured and such implicit knowledge and clinical decisions explicit (Kroppan et al., 2011). A systematic documentation and transference from implicit to explicit knowledge can facilitate an understanding of the actual clinical use of SRAs in daily decision making. This could improve the ability to track the actual clinical use of the SRA, and to make users aware of influence of SRAI. This in turn could improve staff perceptions of clinical usefulness and motivation to use such assessments to guide them.

There was an apparent lack of a consumer perspective (patients, interns, service users) and consumer involvement in the CFIR and in the studies reviewed in study 1, reflecting a research field and clinical practice in which patients are still not involved in their own care (or at least not the part involving risk assessment and management), as suggested in previous research also suggest (Dickens, 2015; Lockertsen et al., 2018; Buch Gudde et al., 2015; Eidhammer et al., 2014). This is alarming considering that laws and clinical guidelines stress the importance of such involvement (SOU, 2004; SOU 2006; Department of Health, 2007; NICE, 2013). The ethical and clinical relevance of SRAIs in forensic psychiatric settings have been criticized due to stigmatizing and facilitating an unreasonable focus on risk (Wand, 2012; Large et al., 2014; Carroll, 2007) that can prevent rather than facilitate recovery. The lack of patient participation in their risk assessments despite these laws and guidelines, as well as research evidence supporting that patients are able to identify mediating factors for violence risk (Olsson et al., 2015; Whinship, 2014; Dickens et al., 2013; Pulsford et al., 2013; Dixon, 2012), does nothing to address these valid concerns.

The characteristics of the outer setting (CFIR) were not mentioned in study 1 or 2 as a determinant of SRAI implementation and use, even though previous research suggests and implementation frameworks imply that this is important (Nilsen et al., 2013; Damshroder et al., 2009). 


\section{Clinical use of structured risk assessment instruments by fidel- ity to risk management plans}

Most of the planned risk management interventions examined in study 3 were realized according to the documentation, both in unstructured clinical assessments and the structured risk assessments. Some interventions, such as restriction of movement outside the ward, are regulated by law and decided by the court, which could explain the high proportion of documented realized interventions. Other potential reasons for a high or low fidelity rate could be access to available resources, patient willingness to participate or not, staff availability and differences in staff perceptions about what specific interventions are important to reduce risk.

Without commonly agreed upon definitions and coding schemes for care and risk management interventions, as well as outcome measures, evaluating the clinical relevance of the findings in study 3 might be difficult. How and to what extent the structured risk assessments influence care and risk management is however an imperative aspect to investigate (Fazel and Björkly, 2016; Elbogen, 2016; Storey et al., 2015; Singh et al., 2014a, 2014b; Sturup et al., 2013; Vojt et al., 2013; Troquete et al., 2013a, 2013b; Wand and Large, 2013; Daffern, 2007;). The findings support the assumed and intended clinical use of SPJIs to influence the provision of care and risk management interventions. Determining what could be considered to be high or sufficient fidelity to planned risk management interventions is, however, also problematic because there are few other studies to compare with (Singh et al., 2014b). More research is needed to confirm these findings. Without such confirmation the clinical relevance of SRAI cannot be concluded with any certainty.

Staff perceived a lack of clinical use of START assessments in study 2. The review of the documentation in study 3 , however, showed that most of the suggested and planned risk management interventions in START and other types of SPJIs used during the study period were realized. These contrasting findings support the previous conclusion that clinical use of SRAIs might sometimes go undetected and that the documentation of such aspects can facilitate understanding and evaluation of actual SPJI use. The extensive and time-consuming efforts required to review the patients' records in study 3 are probably not feasible in a clinical situation. Structured documentation routines specifying the basis for clinical decisions could potentially make such review more time efficient.

The number of realized planned interventions was slightly higher for SPJ assessments compared with UCJ assessments. One might assume that it would be the other way around, that the UCJ planned interventions would be realized more often, considering that the clinicians' (also the ones to 
execute such plans) own assessment of risk and need for interventions should be more easily communicated and accepted by other clinicians and themselves. There are naturally many more UCJ assessments than SPJ assessments in the documentation of forensic care, which also means there might be a greater chance that the UCJ planned interventions are not realized.

Some of the planned risk management interventions were not documented as realized, something that was true for all types of interventions. This could be because some of the planned interventions might not be necessary or appropriate to realize as a result of changes in risk and other circumstances, and some interventions might not be feasible because the patient refused to participate.

Some staff in study 2 was uncertain about to what extent SPJ assessments influenced their clinical decisions and some perceived the SRA did not add anything new to their UCJ. The review of patient records in study 3 confirms there are large overlaps in SPJ and UCJ assessments and risk management plans. This could suggest the staff do already consider relevant risk management interventions in their UCJ assessments as some staff in study 2 suggests. The difference between SPJ and UCJ risk assessments might actually be smaller than thought due to both methods relying on clinical judgements (Baird and Stocks, 2013).

The overlap could also be explained by the long tradition at the clinic to conduct and communicate SPJ assessments to care staff, increasing staff knowledge and improving their UCJ assessments over time. The difference in staff accounts of the influence of SPJ assessments suggests such influence might be implicit and so well integrated in staff perception that they have made such knowledge their own.

The overlap can also be a result of staff and UCJ influence on the SPJ assessment, because the routine of information gathering to conduct the SPJ at the clinic entailed the risk assessor reviewing the clinical documentation and interviewing members of the care team. Hence, the overlap could be a result of a successful mutual interaction and integration of the different type of risk assessments. If this is the case, it might be that both benefit from informing each other to improve assessments and perceived benefit. The perceived relevance and legitimacy and usefulness to staff of SPJ assessment might be improved by UCJ assessment informing SPJ assessment. By the SRA informing the UCJ, these clinical assessments, not recommended in research, might be perceived as more relevant. It would be useful to investigate the relationship between SPJ risk assessment and unstructured clinical assessments and how these assessments influence each other as a measure of the implementation of SPJ assess- 
ments and how such assessments influence and agree with other clinical assessments.

Most of the suggested interventions to prevent violence in SPJ assessments were realized. Because of the large overlap between SPJ and UCJ assessments, it not possible to definitively conclude or confirm the clinical uses of the SRAI in terms of informing and guiding care and risk management interventions. This might also be a result of the UCJ assessments, alone or in addition. An investigation only of the SRAI might have resulted in an incorrect or overly conclusive conclusion about the clinical use of SRAIs, highlighting the importance of casting a wide net and keeping an open mind when trying to understand the impact of SRAIs in clinical settings.

Some interventions were only planned in UCJ assessments, such as limitation of movement on the ward, acute coercion interventions, visitation and some types of assessments. For example, visitations to patients' rooms on the wards are usually motivated by a specific suspicion or as part of the security routine on the wards (often done irregularly). It could be that the assessors in SPJ assessments do not have the same knowledge about the ward and are therefore less able to suggest some types of risk management interventions. Improving such understanding could be facilitated by further communication and mutual information exchange.

For several types of risk management, most of the realized interventions were actually not documented as planned, either in structured or clinical assessments. It may be that some interventions are less suitable or not legal to plan ahead, such as use of coercion (SOSFS 2008:18, National Board of Health and Welfare, 2008). Some interventions can also be part of daily routine care and might therefore not always be documented as planned and/or realized, unless something out of the ordinary occurs. However, what type of care and risk management interventions do not require to be planned ahead needs to be discussed and agreed upon to mitigate subjectivity and arbitrary documentation.

A large part of the care provided does not follow a predetermined plan. Clinicians acting without a predetermined, documented and agreed-upon plan might increase risk of subjectivity and undermine the legal rights of patients, hamper the evaluation of such interventions, and mitigate quality control and follow-up because the reasons for the interventions cannot be traced. These findings confirms it is important to systematically document the basis for clinical decisions even when conducting UCJ assessments, to be able to more accurately evaluate and follow up to see the impact of such assessments in violence prevention, how it compares and relates to the SPJI and to make such data more easily accessible. The basis 
for all provision of care and risk management in forensic settings should be accounted for and documented in patient records (Socialdepartementet, Patientdatalag 2008:355).

More systematic documentation and detailed descriptions of what risk management interventions are actually planned and realized could also be a basis for further research on how different interventions actually mediate risk, protective factors and adverse events in clinical contexts. A discussion about what interventions should be used in different populations and contexts is needed to connect specific risk management interventions with changes in patient behaviour and function and adverse events in future research. In forensic psychiatric care several treatment and risk management interventions are however realized at the same time, making it difficult to conclude the effect of specific interventions. To be able to trace the effect of a specific intervention it needs to be systematically linked to specific pre and post evaluations measures and outcomes related to its specific purpose. As suggested by the participants in study 4 its furthermore not only important to consider what is being done in terms of care and risk management, but also how such interventions are conducted and adapted to them. Involving the patients in the evaluations of the interventions can provide such vital perspectives.

Primary prevention (e.g. assessments and treatments), secondary prevention (e.g. monitoring interventions) and tertiary prevention (e.g. acute coercion interventions) strategies were all noted in the data and support the assumption that reducing risk within a forensic inpatient setting needs to consider a wide range of perspectives and strategies (Allnutt et al., 2013).

\section{Patient perspectives of risk-increasing and risk-decreasing fac- tors for violence}

The findings suggest that there are many different types of factors that influence the risk of violence, according to patient's perceptions. These factors relate to themselves and external influences, social and relational aspects and situational factors. A broad range of factors has also been found in previous research on psychiatric inpatients' perceptions (Pulsford et al., 2013; Meehan et al., 2006; Dickens et al., 2013; Duxbury and Whittington, 2005; Ilkiw and Grenyer, 2003).

Some of the factors influencing violence mentioned by the participants in this study are generic and might seem self-evident because they are applicable to most people. Forensic patients are of course like most people, so this is not unexpected. There might however be a difference in their ability to understand and manage risk-increasing circumstances (especially if 
several factors occur at the same time) at the time of the offence. The participants were sentenced to forced care because they had committed an offence (often some sort of violent act) under the influence of mental illness and had an inherent inability to understand and control their actions at the time of the offence (Annual Forensic Report, 2017).

\section{Risk-increasing factors}

There is a considerable overlap between the risk-increasing factors that the patients perceived to be important and factors included in two SRAIs commonly used in forensic settings to assess and prevent risk of patient violence: HCR-20 (Douglas et al., 2013), SAPROF (de Vogel et al., 2012) and START (Webster et al., 2004), with a few important exceptions.

A few differences to the perceived risk-increasing factors were however found when comparing findings in study 4 with HCR-20 V3 and START. Participants expressed that being ignored and treated badly by care providers was a risk factor for violence, something that is not listed in HCR$20 \mathrm{~V}_{3}$ or START. How professional care providers treat patients has, however, been found to be a mediating factor for the use of violence in previous research investigating forensic patient perceptions (Olsson et al., 2015; Dickens et al., 2013; Jeffs et al., 2012; Chaplin et al., 2006; Carlsson et al., 2006; Meehan et al., 2006; Bensley et al., 1995). Perceiving the behaviour of care providers, themselves and/or colleagues to be a potential cause of violence requires a shift in focus that might be difficult to achieve for many professionals. Offenders' ability to accurately assess and disclose information about their own risk factors have been questioned due to selfserving attributional bias, i.e. the tendency to take credit for success and blame failure on others or external circumstances (Holliday et al., 2013). Findings in this study, however, can be interpreted that care providers as risk assessors might also be subjected to this sort of bias, and forensic patients might actually be more willing to consider others' as well as their own behaviours. The SRAIs define a risk related to the patient's response in terms of not wanting to take the prescribed medication. However, the patients have a wider perspective and also include factors related to the causes of this reaction, i.e. a perceive lack of effect of the medication and severe side effects, as a risk factor. Forensic and psychiatric patients have also been found in previous research to be more concerned about the detrimental effects of medication more often than clinical staff (Dixon, 2012).

Some of the risk-increasing factors mentioned by participants, not listed in either HCR-20 V3 or START as specific risk factors, could be considered in the SPJ procedure of analysing the relevance of different risk fac- 
tors. This includes considering motivational aspects that increase the perceived rewards or benefits of violence, aspects that decrease the perceived costs or negative consequences of violence (called disinhibitors), and aspects that disturb or impair the ability to monitor and control decision making (called destabilizers) (Douglas et al., 2014; Hart and Logan, 2011). Participants identified different types of motivators for their use of violence as risk-increasing factors. This is not listed in HCR-20 or START as a specific risk factor but could be considered when analysing their relevance as motivators. Self-alienation is another example of a riskincreasing factor identified by participants, not mentioned in HCR-20 or START. However, it corresponds with the definition of a destabilizer.

Participants identified some risk-increasing factors for violence not listed in HCR-20 V3 or START, which suggests these aspects might not be considered in the SRAs. However, HCR-20 version 3 and START include options to add relevant individual-specific risk factors not already listed in these instruments. The risk-increasing factors for violence identified in this study not already listed in HCR-20 V3 or START could be considered as additional aspects.

\section{Risk-decreasing factors}

A few risk-decreasing factors identified by participants are not listed in either SAPROF or START. The ability to consider negative consequences rests on abilities such as empathy and cognitive functioning, which are listed in SAPROF and START and described by patients. Actually experiencing negative consequences, as opposed to only imagining them, seemed to be a separate factor according to patients' account, not listed in SAPROF or START. A punitive attitude and/or using care and risk management interventions to punish or set a negative example have no place in forensic psychiatric care or in SRAIs. Some risk-decreasing factors might not be appropriate to include in SRAIs or in care and risk management plans. But talking about the side effects of violence that patients themselves have experienced could still be helpful to mitigate violence risk.

Staff treatment of patients is not mentioned in either SAPROF or START, but described as important by the participants in this study as a means to reduce violence risk. This has also been found in previous research on patient perspectives (Olsson et al., 2015; Meehan et al., 2006; Chaplin et al., 2006a, Chaplin et al., 2006b). The importance of the provision of care and professional support are mentioned in SAPROF and START, but not how this is achieved. 
Although not listed in START or SAPROF, being able to "find and be themselves again and having a sense of who they are", were mentioned by participants as risk-decreasing. Patients' accounts of mediating factors for violence include the inner, personal experiences of using violence and how it relates to their sense of self, which might not be easily captured in SPJIs. The lack of sense of self, i.e. self-alienation, is considered in the SPJ analysis or the relevance of risk factors to act as motivators, destabilizers and disinhibitor. From the patients' description of this aspect in terms of risk reduction, it would be interesting to see if a similar approach could be formulated for risk-decreasing/protective factors.

Despite the overlap of patients' descriptions with START and SAPROF about the risk-decreasing functions of professional care, patients' accounts provides a more detailed description of the specific prerequisites of a functioning health care system and sufficient provision of professional care. The patients have a more comprehensive perspective and talk about the overarching outer context of the health care system and the cooperation between different stakeholders, which is not included in SAPROF or START. This suggests patient might have a wider perspective of mediating factors for violence and can contribute to a wider, as well as more specific, understanding.

The START includes options to add relevant individual-specific risk factors not already listed in these instruments. The risk-decreasing factors for violence identified in this study not already listed in START could be considered as additional aspects, e.g. being locked in, time itself, having a positive experience of care in terms of feeling helped, having a diagnostic assessment, having actual negative experiences of violence, the treatment of staff and self-integration.

\section{Patient participation}

Violence and other adverse events can potentially be mitigated by the provision of forensic care and risk management interventions, guided by SPJ and or UCJ assessments. However, providing the opportunity to engage in treatment interventions most often requires patients to be engaged in and make use of such interventions to have the aimed preventive effect. Adverse events might also be managed and prevented by patients' own initiatives and efforts and their protective factors (Olsson et al., 2015). Patients' own perspectives and endeavours might however not be communicated or documented as systematically as care and risk management interventions provided by care providers (Instefjord, et al., 2014). 
The findings in this study support that patients are themselves active participants in gathering understanding about and continuously managing their own risk of violence using a variety of coping strategies that are in agreement with previous research (Olsson et al., 2015; Dickens et al., 2013; Jeffs et al., 2012; Meehan et al., 2006), reporting that forensic patients used a variety of risk management strategies to prevent violence such as motivating and encouraging themselves, improving their understanding, engaging in treatment, managing feelings of aggression, accepting their situation, thinking about consequences and assuming responsibility, attending to warnings signs and avoiding use of substances, withdrawing from conflict situations, and so forth.

A person's ability to accurately disclose potential negative information about themselves can be hindered by self-enhancement bias, self-serving attributional bias and limited self-awareness, as well as fear of negative consequences (and expectations of consequences, such as increased restrictions; Holliday et al., 2013). How well patients are able to disclose information about themselves can also depend on the way researchers and clinicians involve the patient in the discussion and ask the questions (Skeem et al., 2013). However, previous research suggests that when patients are not restricted by thoughts of consequences to care, they can assess their risk potentially more accurately than unaided clinical risk assessment conducted by staff (Skeem et al., 2013).

Several efforts were made to facilitate the participants' ability to speak freely, such as ensuring anonymity and emphasizing that their statements would never be communicated to their care providers and would not affect their care in any way. The participants in this study did disclose many different risk-increasing factors relating both to the external environment as well as to themselves. Most participants seemed to take their own risk for future violence very seriously. The large overlap between the findings in this study and risk factors mentioned in SPJ instruments derived from research evidence further supports that patients are well aware of and able to identify and communicate relevant and research supported mediating factors for violence.

It might be suggested that the participants' understanding of mediating factors for violence are influenced by the structured risk assessments and the care provided, which explains the overlap between them. Some participants did provide examples of how different aspects of the care provided had helped them understand the mediating factors for their violence. The concurrent accounts and histories provided by the patients and the many concrete examples they provided suggest the findings in this study really are the participants' own perceptions. They vividly described the process of coming to terms with their violence risk and how such insights and un- 
derstanding were often hard earned and painful, and a result of their own endeavours.

The wide variety of risk-decreasing aspects, confirmed by research, and mention of strategies to prevent violence suggest that forensic patients are capable, knowledgeable and active partners in reducing their risk of violence. This might seem contradictory considering they were still under forced care and hence deemed to be under the influence of a major mental illness and/or posing a risk for doing harm to themselves and/or others. The ability of mentally ill offenders to participate in risk assessment and research has also been questioned due to psychiatric symptoms and cognitive deficits rendering them unable to consider all relevant information (Holliday et al., 2013). But even patients who are often violent do not use violence every day, and they are most often able to prevent themselves from acting violently. Even though you might understand the mediating factors for your violence, some things are easier said than done, and you might not always be able to uphold the insights or use the risk management strategies you have successfully enough.

The lack of a patient's perspective and participation in implementation frameworks, research and risk assessments in forensic psychiatric settings is alarming, considering laws and clinical guidelines clearly stress the importance of such involvement. The ethical soundness and clinical relevance of SPJ risk assessments in forensic psychiatric settings have been criticized due to the risk of stigmatizing and facilitating an unreasonable focus on risk and restrictions. The lack of patient participation in their risk assessments despite these laws and guidelines, as well as research evidence supporting that patients are knowledgeable about mediating factors for violence risk, does nothing to contradict such criticism.

Restricting the freedom of and imposing treatment on mentally ill patients based on the harm they might or might not impose to themselves or others in the future will always be ethically challenging. By implementing risk assessment instruments with the structured professional judgement approach, with fidelity to the manuals and evidence based practice recommendations, being mindful of and clear about their purpose and limitations, including protective factors and a recovery focus and involving patients in these risk assessments and research as much as possible, some of the ethical problems can be limited. The use of structured risk assessment instruments has been found to de-stigmatise mentally ill patients (MacGabhann, et al., 2002).

There is a large overlap between planned care and risk management interventions to prevent violence and other adverse events in SRA and UCJ found in study 3. Staff also perceived that their UCJ already considered 
the risk and protective factors and treatment needs identified in the SRA. There is also a large overlap between what research, SRAI and forensic patients perceive to be relevant risks and protective factors. The SPJ approach includes gathering information from relevant stakeholders to do the risk assessment, which can include clinicians, file records and patients. It also includes documentation and communication informing stakeholders of risk, risk and protective factors and suggestions for care and risk management. This intended/assumed mutual information among all stakeholders involved in conducting and using SRAs was confirmed in this thesis as suggested by these overlaps.

The overlap and mutual information among stakeholders further suggest that there are common grounds for cooperation among risk assessors, clinicians and patients to assess risk and to plan interventions to prevent adverse events and promote recovery. Recognizing this mutual understanding and that the differences might not be as large as perhaps expected might facilitate improved respect and interest in further cooperation and provide a platform for dialogue about the often minor differences in what needs to be done and how to prevent adverse events.

\section{Methodological considerations}

The studies have limitations that must be considered when interpreting the findings. This section discusses some methodological aspects encountered in the thesis studies.

Confirmability relates to efforts to prevent the researcher's preconceptions affecting the results instead of the informants' responses, which is enhanced by reflexivity about possible researcher bias (Patton, 2002). The first author (SL) is a clinical psychologist at the clinic and was also part of the implementation project (study 2) as a research administrator responsible for evaluating the project. Such familiarity might have made this author subjected to influence of preconceptions. However, several efforts were made to mitigate such bias. During the interviews with staff and patients, the first author made efforts not to assume to understand unspoken or implied references and encouraged informants to describe what they meant and what they were referring to. Being known to some participating staff could also have affected the staffs' ability to speak freely in the focus group interviews. The first author specifically asked for both positive and negative opinions, and the data analysis also shows that participants could express critique.

Efforts were made to reduce the risk of bias related to preconceived notions of the first author influencing SL, as well confirmation and selection 
and interpretation bias, and hence also the credibility (Patton, 2002). The data gathering and analysis process were triangulated with the other authors in the thesis studies. These researchers have diverse professional and research backgrounds and are not involved in clinical practice or research on risk assessment instruments. During the analysis, the original data were also continuously consulted.

The sampling process and the small study populations make statistical generalization of the findings in the thesis studies difficult. An analytical and theoretical generalization was instead sought by comparing findings with theories, frameworks, previous research studies and SRAIs. The findings are in line with previous research using different methodologies and larger numbers of participants, when such studies exist. Using other means of investigating patients' perceptions, such as surveys or focus group interviews, could potentially have incorporated forensic patients who are not comfortable with the individual interview format and provide additional perspectives on mediating factors for violence (Doyle and Leonard, 2016).

Dependability refers to the consistency of the data and the possibility of repeating the study and the findings (Patton, 2002). The often inconsistent and poor quality of the studies reviewed in study 1 , the potentially inconsistent and underreporting by staff in patient records, as well as potential limitations in the staffs' and patients' ability to express their perceptions during the interviews, might have created unreliable findings. Other researchers might also have defined the categories in studies 2, 3 and 4 differently. To facilitate transparency and the ability to trace findings to the data gathering and analysis processes, the motivation and description of these steps have been provided for the thesis studies. The provision of quotes and extracts also aimed to facilitate such transparency. 


\section{CONCLUSIONS}

The findings in the thesis contribute to an improved understanding of the implementation and clinical use of structured risk assessment instruments in forensic psychiatric care, regarding research and practice.

A multifaceted approach addressing implementation aspects at several different system levels is needed when implementing an SRAI in forensic settings. Grasping and continuously addressing the confounding aspects at different stages of the process, as well as adapting interventions to the different needs of different stakeholder are highly complicated. It is easy to underestimate the time and resources required.

There is evidence of clinical use of structured professional judgement instruments in terms of informing and guiding care and risk management interventions. The large overlaps between the planned risk management interventions in structured and unstructured risk assessments, however, make it difficult to draw definite conclusions about how the type of assessment influenced the realized interventions. It is important to consider both types of risk assessment and patients own efforts to prevent adverse events when investigating the clinical relevance of SPJ risk assessments.

Most realized care and risk management interventions are not planned, which increases the risk of subjectivity and arbitrary decisions in the provision of interventions. Such interventions are also more difficult to evaluate. This is serious considering forensic psychiatric care involves restriction of patient freedom and civil rights.

Forensic psychiatric patients are capable and important participants in the much needed research to improve the knowledge and understanding of the forensic population and what interventions and treatments are beneficial. They can provide additional perspectives of mediating factors for violence risk. The lack of the patient's perspective and participation in implementation frameworks, research and risk assessments in forensic psychiatric settings is alarming.

The overlap between structured and unstructured risk assessments and patients perceptions about mediating factors for violence and care and risk management suggest there are common grounds for improved cooperation. 
By implementing risk assessment instruments with the structured professional judgement approach with fidelity to the manuals and evidence based practice recommendations, being mindful of and clear about their purpose and limitations, including protective factors and a recovery focus and involving patients in these risk assessments and research, some of the ethical problems related to this practice can be limited. 


\section{IMPLICATIONS FOR FURTHER RESEARCH}

Further and more stringent research on implementation of structured risk assessment instrument in forensic psychiatric care is needed to obtain additional solid evidence of the factors that impede or enable this implementation. Research is also needed to understand whether there are differences between implementation determinants in different settings and with different SRAIs. There is also a need for definitions and measures for successful and failed implementation outcomes to allow comparisons of implementation studies and best practice. Constructing and refining shared concepts and definitions of determinants could further aid information transference and accumulation of an international body of knowledge.

More research is required to understand what is needed to change a culture focused on risk and how to facilitate better inclusion of protective factors in SRAs in forensic psychiatric care. What staffs need to translate a documented SRA into everyday clinical application in specific situations also needs further investigation.

Further research and a debate about what constitutes reasonable levels of fidelity to risk management plans in SRA is needed. Such understanding could also be facilitated if the reasons for cancellation of planned interventions were more stringently documented. A more systematic documentation and detailed descriptions of what risk management interventions are actually planned and realized could also be a basis for further research on how different interventions actually mediate risk, protective factors and adverse events in clinical contexts.

To improve the understanding of what actually mitigates violence and other adverse events future research needs to consider these barriers to patient involvement in risk assessments, care and risk management planning as well as realizing and evaluation of interventions to reduce such risk. The relationships between SPJ risk assessment and unstructured clinical assessments, as well as patients' own efforts, and how these influence each other, needs further investigation to facilitate understanding their respective roles in preventing adverse events. Further research is specifically needed on to what extent and how forensic psychiatric patients themselves are involved in risk assessments conducted as part of 
their care and how such participation can be facilitated. Including patients in such research is warranted.

A detailed description of what risk management interventions are actually planned and realized could also be a basis for further research on how different interventions actually mediate risk, protective factors and adverse events in clinical contexts, and a discussion about what interventions should be used in different populations and contexts. In order to connect specific risk management interventions to changes in patient behaviour and function and adverse events in future research, the definitions might need to be defined in more detail. 


\section{ACKNOWLEDGEMENTS}

I would like to express my sincere gratitude to a number of people.

My supervisors Preben Bendtsen, Per Nilsen and Per Bülow for guiding and supporting me throughout this dissertation project. Thank you for your advice and guidance in times of confusion, your patience with my strong will and inability to express myself with few words instead of many, and being such excellent role models of highly skilled, yet unpretentious researchers and professionals.

The forensic patients for their invaluable contribution. Your willingness to share your often difficult experiences and hard-learned lesson is paramount to inform research of forensic populations in general and this thesis in particular.

My gratitude extends also to the patients I have met during my years as a clinician. I learn so much from you; your struggles humble me and give me perspective; your courage in facing problems inspires me and gives me hope.

The staff for taking the time to take part in the focus group interviews and sharing your experiences and thoughts, despite a hectic schedule.

All my colleagues at the regional forensic psychiatric clinic in Vadstena, you make every day inspiring and fun.

My employer Region Östergötland, my boss Jan Cederborg, and our head of research at the clinic Henrik Belfrage, for allowing and encouraging me to do this dissertation project.

To my senior research colleague Kenneth Rydenlund for your support and inspiring ability to be genuine and true to your values no matter what.

Peter Karlberg for being my IT angel, fixing my computer when I was ready to throw it out the window.

Tomas Malmqvist for helping me with the records, and for your loyalty and willingness to support your colleagues. 
My family for reminding me about what is most important and providing me with balance in life.

Vincent, being your mother is the greatest joy and adventure of my life, your wonderfully curious mind and wilful spirit always inspire me.

Oskar and Sofia, my wonderful bonus children for the joy you brought into my life so unexpectedly; you truly are a bonus in my life.

My awesome mother, for always loving and supporting me whatever I did in life; you make me believe in myself and that I can do anything.

My beloved brothers, for always being by my side and keeping me real.

Natalie, my best friend, for making me laugh and dragging me away from home every now and then to go on adventures.

Torbjörn, for showing me the meaning of true love and anchoring me when I tend to drift away.

I would also like to thank my stepfather Dick who passed away last December, for restoring my broken faith in father figures, setting a good example for a strong work ethic and teaching me that anything worth doing is worth doing well.

Thank you all. 


\section{REFERENCES}

Allnutt, S.H., Ogloff, J.R.P., Adams, J., O’Driscoll, C., Daffern, M., Carroll, A., Nanayakarra, V., Chaplow, D. (2013). Managing aggression and violence: the clinician's role in contemporary mental health care. Australian \& New Zealand Journal of Psychiatry, 47, 728-776. doi: 10.1177/0004867413484368.

Annual Forensic Report (2016). Nationellt rättspyskiatriskt kvalitetsregister. Göteborg: Regionstyrelsen i Västra Götalandsregionen. Sweden.

Annual Forensic Report (2017). Nationellt rättspyskiatriskt kvalitetsregister. Göteborg: Regionstyrelsen i Västra Götalandsregionen. Sweden.

Arbisi, P.A. (2016). Mitigating risk: commentary on performance of protective factors assessment in risk prediction for adults: systematic review and meta-analysis. Clinical Psychology Science and Practice, 23, 139-141. doi:10.1111/cpsp.12145.

Baird, J., Stocks, R. (2013). Risk assessment and management: forensic methods, human results. Advances in pscychiatric treatment, 19, 358-365. doi: 10.1192/apt.bp.111.009407.

Bensley, L., Nelson, N., Kaufman, J., Silverstein, B., Walker Shields, J. (1995). Patient and staff views of factors influencing assaults on psychiatric hospital employees. Issues in Mental Health Nursing, 16, 433-446. doi: 10.3109/01612849509006944.

Bhui, K., Outhwaite, J., Pereira, S., Strathdee, G., Adzinku, F., Dixon, P. (2000). New guidelines on managing violence. British Journal of Health Care Management, 6, 415-419.

Boer, D.P., Hart, S.D., Kropp, P.R., Webster, C.D. (1997). Manual for the Sexual Violence Risk - 20. Professional Guidelines for Assessing Risk of Sexual Violence. Simon Fraser University, Canada: The Mental Health, Law, \& Policy Institute.

Borum, R. (2003). Managing at-risk juvenile offenders in the community: putting evidence-based principles into practice. Journal of Contemporary Criminal Justice, 19, 114-137.

Borum, R., Bartel, P., Forth, A. (2006). Manual for the Structured Assessment of Violence Risk in Youth (SAVRY). Odessa, FL: Psychological Assessment Resources.

Buch Gudde, C., Möller Olsö, T., Whittington, R., Vatne, S. (2015). Service users' experiences and views of aggressive situations in mental health care: a systematic review and thematic synthesis of qualitative studies. Journal of Multidisciplinary Healthcare, 8, 449-462. doi.org/10.2147/JMDH.S89486.

Carlsson, G., Dahlberg, K., Ekebergh, M., Dahlberg, H. (2006). Patients longing for authentic personal care: A phenomenological study of violent encoun- 
ters in psychiatric settings. Issues in Mental Health Nursing, 27 (3), 287305, doi: 10.1080/01612840500502841.

Carroll, A. (2007). Are violence risk assessment tools clinically useful? Australian and New Zeeland Journal of Psychiatry, 41, 301-307.

Carroll, A. (2008). Forensic Psychiatry: Risk assessment and management in practice: the Forensicare Risk Assessment and Management Exercise. Australasian Psychiatry, 16 (6), 412-414. Doi: 10.1080/10398560802068942.

Carroll, A. (2009). How to make good-enough risk decisions. Advances in psychiatric treatment, 15, 192-198. doi: 10.1192/apt.bp.107.005439.

Chaplin, R., McGeorge, M., Lelliott, P. (2006a) Violence on inpatient units for people with learning disability and mental Illness: The experiences ofservice users and staff. The British Journal of Development Disabilities, 52:103, 109-116, doi: 10.1179/096979506799103532.

Chaplin, R., McGeorge, M., Lelliott, P. (2006b). In-patient care for working-age adults: The National Audit of Violence: in-patient care for adults of working age. Psychiatric Bulletin, 30, 444-446.

Clarke, D.E., Brown, A.-M., and Griffith, P. (2010). The Brøset Violence Checklist: clinical utility in a secure psychiatric intensive care setting. Journal of Psychiatric and Mental Health Nursing, 17, 614-620.

Cohn, A. (2002). Managing the correctional enterprise - the quest for "what works". Federal Probation, 66(2): 4-9.

Cooke, D., J., Michie, C. (2009). Limitations of Diagnostic Precision and Predictive Utility in the Individual Case: A Challenge for Forensic Practice. Law Hum Behav, 34, 259-274. doi: 10.1007/s10979-009-9176-x.

Coffey, M. (2012). A risk worth taking? Value differences and alternative risk constructions in accounts given by patients and their community workers following conditional discharge from forensic mental health services, Health, Risk \& Society, 14 (5), 465-482. doi:10.1080/13698575.2012.682976.

Crocker, A.G., Braithwaite, E., Laferrière, D., Gagnon, D., Venegas, C., Jenkins, T. (2011). START changing practice: implementing a risk assessment and management tool in a civil psychiatric setting. International Journal of Forensic Mental Health, 10, 13-28. doi:10.1080/14999013.2011.553146.

Daffern, M. (2007). The predictive validity and practical utility of structured schemes used to assess risk for aggression in psychiatric inpatient settings. Aggression and Violent Behavior, 12, 116-130. doi:

10.1016/j.avb.2006.03.005.

Damschroder, L.J., Aron, D.C., Keith, R.E., Kirsh, S.R., Alexander, J.A., Lowery, J.C. (2009). Fostering implementation of health services research findings into practice: a consolidated framework for advancing implementation science. Implementation Science, 4, 50. doi: 10.1186/1748-5908-4-50.

de Ruiter, C., Nicholls, T.L. (2011). Protective factors in forensic mental health: a new frontier. International Journal of Forensic Mental Health, 10, 160170. doi: 10.1080/14999013.2011.600602 
de Vogel, V., de Ruiter, C., Bouman, Y.H.A., de Vries Robbé, M. (2012). SAPROF Structured Assessment of PROtective Factors for Violence Risk. Utrecht, Netherlands: van der Hoeven Stichting.

de Vries Robbé, M., de Vogel, V., Douglas, K.S. (2013). Risk factors and protective factors: a two-sided dynamic approach to violence risk assessment. Journal of Forensic Psychiatry \& Psychology, 24, 440-457. doi: 10.1080/14789949.2013.818162.

de Vries Robbé , M., de Vogel, V., de Spa, E. (2011). Protective factors for violence risk in forensic psychiatric patients: A retrospective validation study of the SAPROF. International Journal of Forensic Mental Health, 10 (3), 178-186, doi: 10.1080/14999013.2011.600232.

de Vries Robbé, M., de Vogel, V., Koster, K., Bogaerts, S. (2015). Assessing protective factors for sexually violent offending with the SAPROF. Sexual Abuse: A Journal of Research and Treatment, 27(1), 51-70. doi:10.1177/1079063214550168.

Deci, E., L., Ryan, R., M. (2000). Self-determination theory and the facilitation of intrinsic motivation, social development, and well-being. American Psychologist, 55 (1), 68-78. doi: 10.1037110003-066X.55.1.68

Department of Health (2007). Best practice in managing risk. Prepared for the National Risk Management Program. London: Department of Health.

Desmarais, S.L. (2017). Commentary: Risk assessment in the age of evidencebased practice and policy. International Journal of Forensic Mental Health, 16, 18-22, doi:10.1080/14999013.2016.1266422.

Dickens, G.L. (2015). Re- focusing risk assessment in forensic mental health nursing. Journal of Psychiatric and Mental Health Nursing, 22, 461-462. doi: 10.1111/jpm.12256.

Dickens, G., Piccirillo. M., Alderman, N. (2013). Causes and management of aggression and violence in a forensic mental health service: perspectives of nurses and patients. International Journal of Mental Health Nursing, 22, 532-544. doi: 10.1111/j.1447-0349.2012.00888.x

Dixon, J. (2012). Mentally disordered offenders' view of "their" risk assessment and management plans. Health, Risk \& Society, 14, 667-680.

Douglas, S.D. (2014). Version 3 of the Historical-Clinical-Risk Management-20 (HCR-20V3): relevance to violence risk assessment and management in forensic conditional release contexts. Behavioral Sciences and the Law, 32, 557-576. doi: 10.1002/bsl.2134.

Douglas, K.S., Belfrage, H. (2014) Interrater reliability and concurrent validity of the HCR-20 Version 3. International Journal of Forensic Mental Health, 13, 130-139. doi: 10.1080/14999013.2014.908429.

Douglas, K.S., Skeem, J.L. (2005). Violence risk assessment - getting specific about being dynamic. Psychology, Public Policy, and Law, 11, 347-383. doi: 10.1037/1076-8971.11.3.347.

Douglas, K.S., Hart, S.D., Webster, C.D., Belfrage, H. (2013). HCR-2O V3 Assessing Risk for Violence. Simon Fraser University: Mental Health, Law, and Policy Institute. 
Douglas, K., S., Hart, S., D., Webster, C., D., Belfrage, H., Guy, L., S., Wilson, C., M. (2014). Historical-Clinical-Risk Management-20, Version 3 (HCR20V3): Development and Overview. International Journal of Forensic Mental Health, 13: 93-108. doi: 10.1080/14999013.2014.906519.

Douglas, T., Pugh, J., Singh, J.P.I., Savulescu, J., Fazel, S. (2017). Risk assessment tools in criminal justice and forensic psychiatry: the need for better data. European Psychiatry, 42, 134-137. doi: 10.1016/j.eurpsy.2016.12.009 0924-9338.

Doyle, M.D., Logan, C. (2012). Operationalizing the assessment and management of violence risk in the short-term. Behavioral Sciences and the Law, 30, 406-419. doi: 10.1002/bsl.2017.

Doyle, M., Leonard, S-J. (2016). The current state of violence risk assessment in England and Wales. In: Singh, J.P., Björkly, S., Fazel, S. (Eds.), International Perspectives on Violence Risk Assessment. New York: Oxford University Press. doi:10.1093/acprof:oso/9780199386291.003.0021.

Doyle, M., Lewis, G., Brisbane, M. (2008). Implementing the Short term Assessment of Risk and Treatability (START) in a forensic mental health service. Psychiatric Bulletin, 32, 406-408. doi: 10.1192/pb.bp.108.019794.

Dressing , H., Salize, H.J. (2004). Compulsory admission of mentally ill patients in European Union Member States. Social Psychiatry and Psychiatric Epidemiology, 39, 797-803. doi: 10.1007/s00127-004-0814-9.

Duxbury, J., Whittington, R. (2005). Causes and management of patient aggression and violence: staff and patient perspectives. Journal of Advanced Nursing, 50, 469-478.

Eidhammer, G., Fluttert, F.A.J., Björkly, S. (2014). User involvement in structured violence risk management within forensic mental health facilities - a systematic literature review. Journal of Clinical Nursing, 23, 2716-2724. doi: 10.1111/jocn.12571.

Elbogen, E.B. (2002). The process of violence risk assessment: a review of descriptive research. Aggression and Violent Behaviour, 7, 591-604.

Elbogen, E.B. (2016). The process and context of violence risk assessment Toward integrating science into clinical practice. In: Singh, J.P., Björkly, S., Fazel, S. (Eds.), International Perspectives on Violence Risk Assessment. New York: Oxford University Press. doi:10.1093/acprof:oso/9780199386291.003.0005.

Fazel, S., Björkly, S. (2016). Methodological considerations in risk assessment research. In: Singh, J.P., Björkly, S., Fazel, S. (Eds.), International Perspectives on Violence Risk Assessment. New York: Oxford University Press. doi:10.1093/acprof:oso/9780199386291.003.0002.

Fazel, S., Hayes, A.J., Bartellas, K., Clerici, M., Trestman, R. (2016). The mental health of prisoners: a review of prevalence, adverse outcomes and interventions. Lancet Psychiatry, 3, 871-881. doi: 10.1016/S22150366(16)30142-0.

Ferguson, J.L. (2002). Putting the "what works" research into practice: An organizational perspective. Criminal Justice and Behaviour, 29, 472-492. 
Ghio, L., Zanelli, E., Gotelli, S., Rossi, P., Natta, W., Gabrielli, F. (2011). Involving patients who attempt suicide in suicide prevention: a focus group study. Journal of Psychiatric and Mental Health Nursing, 18, 510-518. doi: 10.1111/j.1365-2850.2011.01697.x.

Graneheim, U.H., Lundman, B. (2004). Qualitative content analysis in nursing research: concepts, procedures and measures to achieve trustworthiness. Nurse Education Today, 24, 105-112. doi:10.1016/j.nedt.2003.10.001.

Gough, K., Richardson, C., Weeks, H. (2015). An audit of service-user involvement and quality of HCR-20 version 2 risk assessments on rehabilitation and low secure wards. Journal of Psychiatric Intensive Care, 11. doi:10.1017/S1742646415000084.

Grimshaw, J., Eccles, M., Thomas, R., MacLennan, G., Ramsay, C., Fraser, C., et al. Toward evidence-based quality improvement. Evidence (and its limitations) of the effectiveness of guideline dissemination and implementation strategies 1966-1998. Journal of General Internal Medicine, 21, 14-20.

Grisso, T. \& Vincent, G., M. (2005). The empirical limits of forensic mental health assessment. Law and Human Behaviour, 29 (1), 1-5. doi: 10.1007/s10979-005-1396-0.

Guevara, M., Solomon, E. (2009). Implementing Evidence-Based Practice in Community Corrections. The Principles of Effective Intervention. 2nd edition. Boston, MA: Crime and Justice Institute; Washington, DC: National Institute of Corrections.

Guy, L.S., Packer, I.K., Warnken, W. (2012). Assessing risk of violence using structured professional judgment guidelines. Journal of Forensic Psychology Practice, 12, 270-283. doi: 10.1080/15228932.2012.674471.

Haque, Q. (2016). Implementation of violence risk assessment instruments in mental healthcare settings. In: Singh, J.P., Björkly, S., Fazel, S. (Eds.), International Perspectives on Violence Risk Assessment. New York: Oxford University Press. doi:10.1093/acprof:oso/9780199386291.003.0004.

Hague, Q., Cree, A., Webster, C., Hasnie, B. (2008). Best practice in managing violence and related risks. The Psychiatrist, 32, 403-405.

Hall, S., Duperouzel, H. (2011). "“We know about our risks, so we should be asked." A tool to support service user involvement in the risk assessment process in forensic services for people with intellectual disabilities", Journal of Learning Disabilities and Offending Behaviour, 2 (3), 122-126. https://doi.org/10.1108/20420921111186598.

Hallett, N., Huber, J.W., Dickens, G.L. (2014). Violence prevention in inpatient psychiatric settings: systematic review of studies about the perceptions of care staff and patients. Aggression and Violent Behavior, 19, 502-514.

Hart, S., D., Logan, C. (2011). Formulation of Violence Risk Using EvidenceBased Assessments: The Structured Professional Judgment Approach. In: Sturmey, P., McMurran, M. (Eds.), Forensic case formulation. WileyBlackwell.

Hart S.D., Douglas, K.S., Guy, L.S. (2016). The structured professional judgment approach to violence risk assessment: origins, nature, and advances. In: Boer, D.P., Beech, A.R., Ward, T., Craig, L.A., Rettenberger, M., Marshall, 
L.E., Marshall, W.L. (Eds.), The Wiley Handbook on the Theories, Assessment, and Treatment of Sexual Offending. Wiley-Blackwell. pp. 643-666. doi: 10.1002/9781118574003.wattsoo30.

Hart, S.D., Kropp, P.R., Laws, D.R., Klaver, J., Logan, C., Watt, K.A. (2003). The Risk for Sexual Violence Protocol (RSVP). Burnaby, BC: Simon Fraser University, Mental Health, Law, and Policy Institute.

Heilbrun, K. (1997). Prediction versus management models relevant to risk assessment: the importance of legal decision-making context. Law and $\mathrm{Hu}$ man Behavior, 21, 347-359.

Hogan N.R., Olver, M.E. (2016). Assessing risk for aggression in forensic psychiatric inpatients: an examination of five measures. Law and Human Behavior, 40, 233-243. doi: 10.1037/lhboooo179.

Hogan, N.R., Olver, M.E. (2018) A prospective examination of the predictive validity of five structured instruments for inpatient violence in a secure forensic hospital. International Journal of Forensic Mental Health, 17, 122132. doi: 10.1080/14999013.2018.1431339.

Holliday, S.B, King, C., Heilbrun, K. (2013). Offenders perceptions of risk factors for self and others: theoretical importance and some empirical data. Criminal Justice and Behaviour, 40, 1044-1061.

Hsieh, H.-F., Shannon, S.E. (2005). Three approaches to qualitative content analysis. Qualitative Health Research, 15, 1277-1288. doi: $10.1177 / 1049732305276687$.

Hylander, I. (2001). Fokusgrupper som kvalitativ datainsamlingsmetod (FOG Report 42). Linköping: Institutionen för beteendevetenskap, Linköping University.

Ilkiw, O., Grenyer, B.F.S. (2003). Differences between patient and staff perceptions of aggression in mental health units. Psychiatric Services, 54, 389393 .

Instefjord, M., H., Aasekjaer, K., Espehaug, B., Graverholt, B. (2014). Assessment of quality in psychiatric nursing documentation - a clinical audit. BMC Nursing, 13 (32). doi:10.1186/1472-6955-13-32.

Jeffs, L., Rose, D., Macrae, C., Maione, M., Macmillan, K., M. (2012). What near misses tell us about risk and safety in mental health care Journal of Psychiatric and Mental Health Nursing, 19, 430-437. doi: 10.1111/j.13652850.2011.01812.x.

Johnson, B., Martin, M.-L., Guha, M., Montgomery, P. (1997). The experience of thought-disordered individuals preceding an aggressive incident. Journal of Psychiatric and Mental Health Nursing, 4, 213-220.

Judges, R., Egan, V. \& Broad, G. (2016). A critique of the Historical Clinical Risk- 20, Version 3, Risk assessment instrument. Journal of Forensic Psychology Practice, 16 (4), 304-320. doi: 10.1080/15228932.2016.1196102.

Kaunomäki, J., Jokela, M., Kontio, R., Laiho, T., Sailas E., Lindberg, N. (2017). Interventions following a high violence risk assessment score: a natural- 
istic study on a Finnish psychiatric admission ward. BMC Health Services Research, 17. doi:10.1186/s12913-016-1942-0.

Keune, L., H., de Vogel, V., van Marle, H., J., C. (2016). Methodological development of the Hoeven Outcome Monitor (HOM): A first step towards amore evidence basedmedicine in forensic mental health. International Journal of Law and Psychiatry, 45, 43-51. http://dx.doi.org/10.1016/j.ijlp.2016.02.009.

Knox, D.K., Holloman, G.H.(2012). Use and avoidance of seclusion and restraint: consensus statement of the American Association for Emergency Psychiatry Project BETA Seclusion and Restraint Workgroup, Western 35. Journal of Emergency Medicine, 3, 35-40. doi: 10.5811/westjem.2011.9.6867.

Konrad, N. (2016). Ethical issues on forensic-psychiatric examinations. Ethics, Medicine and Public Health, 2, 119-126. http://dx.doi.org/10.1016/j.jemep.2016.01.016.

Kontio, R., Anttila, M., Lantta, T., Kauppi, K., Joffe, G., Välimäki, M.(2013). Toward a safer working environment on psychiatric wards: service users' delayed perspective of aggression and violence-related situations and development ideas. Perspectives in Psychiatric Care, 50, 271-279. doi. 10.1111/ppc.12054.

Krimiminalvården klientkartläggning. (2013). Ett regeringsuppdrag - En presentation av bakgrundsfaktorer hos krimialvårdens klienter. www.kriminalvarden.se/sv/Publikationer

Kroner, D.G. (2012). Service user involvement in risk assessment and management: The Transition Inventory. Criminal Behaviour and Mental Health, 22, 136-147. doi: 10.1002/cbm.1825.

Kroppan, E., Nonstad, K., Iversen, R., B., Sondenaa, E. (2017). Implementation of the Short-Term Assessment of Risk and Treatability over two phases. Journal of Multidisciplinary Healthcare, 10, 321-326. http://dx.doi.org/10.2147/JMDH.S133514.

Kroppan, E., Nesset, M.B., Nonstad, K., Pedersen, T.W., Almvik, R., Palmstierna, T. (2011). Implementation of the Short-Term Assessment of Risk and Treatability (START) in a forensic high secure unit. International Journal of Forensic Mental Health, 10, 7-12. doi: 10.1080/14999013.2011.552368.

Langan, J. (2010). Challenging assumptions about risk factors and the role of screening for violence risk in the field of mental health. Health, Risk \& Society, 12, 85-100. doi: 10.1080/13698571003632429.

Lanza, M.L., Kayne, H.L. (1995). Patient assault: a comparison of patient and staff perceptions. Issues in Mental Health Nursing, 16, 129-141. doi: 10.3109/01612849509006930.

Large, M.M., Ryan, C.J., Callaghan, S., Paton, M.B., Singh, S.P.( 2014). Can violence risk assessment really assist in clinical decision-making? Australian \& New Zealand Journal of Psychiatry, 48, 286-288. doi: 10.1177/0004867413498275. 
Large, M., Nielssen, O. (2017). Perspectives: The limitations and future of violence risk assessment. World Psychiatry, 16. doi:10.1002/wps.20394.

Lidz, C.W., Mulvey, E.P., Gardner, W. (1993). The accuracy of predictions of violence to others. Journal of the American Medical Association, 8, 10071011. doi: 10.1001/jama.1993.03500080055032.

Livingston, J.D., Nijdam-Jones, A., Lapsley, S., Calderwood, C., Brink, J. (2013). Supporting recovery by improving patient engagement in forensic mental health hospital: results from a demonstration project. Journal of the American Psychiatric Nurses Association, 19, 132-145.

Lockertsen, Ö., Procter, N., Bø Vatnar, S.K., Færden, A., Eriksen, B.M.S., Roaldset, J.O., Varvin, S. (2018). Screening for risk of violence using service users 'self-perceptions: a prospective study from an acute mental health unit. International Journal of Mental Health Nursing, 27, 1055-1065. doi: 10.1111/inm.12413.

MacGabhann, L., Baker, S., Dixon, P. (2002). Prevention and management of violence: implementing clinically effective practice. Mental Health Practice, 6(2), 8-13. doi: 10.7748/mhp2002.10.6.2.8.c1738.

MacKenzie, R., McEwan, T., Pathé, M., James, D., Ogloff, J., Mullen, P. (2009). The Stalking Risk Profile: Guidelines for the Assessment and Management of Stalkers. Melbourne: Stalk Inc. and Centre for Forensic Behavioural Science, Monash University.

Maguire, T., Daffern, M., Bowe, S., J. and McKenna, B.(2017). Risk assessment and subsequent nursing interventions in a forensic mental health inpatient setting: associations and impact on aggressive behavior. Journal of Clinical Nursing, 27, e971-e983. doi: 10.1111/jocn.14107.

Magyar M., Edens J.F., Epstein, M., Stiles, P.G., Poythress Jr., N.G. (2012). examining attitudes about influences on research participation among forensic psychiatric inpatients, Behavioural Sciences \& the Law, 30, 69-86. doi: 10.1002/bsl.1997.

Mayring, P. (2000). Qualitative content analysis. Forum: Qualitative Social Research, 1, 20. doi: 10.17169/fqs-1.2.1089.

Meehan T., McIntosh, W., Bergen H. (2006). Aggressive behaviour in the high secure forensic setting: the perception of patients. Journal of Psychiatric and Mental Health Nursing 13, 19-25.

Monahan, J., Skeem, J. L. (2014). The evolution of violence risk assessment. CNS Spectrums, 19, 419-424. doi:10.1017/S1092852914000145.

Mullen, A., Drinkwater, V., Lewin, T. (2013). Care zoning in a psychiatric intensive care unit: strengthening ongoing clinical risk assessment. Journal of Clinical Nursing, 23, 731-743.

Murray, J., Thomson, M., E. (2010). Clinical judgement in violence risk assessment. Europe's Journal of Psychology, 1, 128-149.

Nedopil, N. (2009). The role of forensic psychiatry in mental health systems in Europe. Criminal Behaviour and Mental Health, 19, 224-234. doi: 10.1002/cbm.719. 
NICE (2007). Best Practice in Managing Risk: Principles and Evidence for Best Practice in the Assessment and Management of Risk to Self and Others in Mental Health. London: NICE.

NICE (2013) Patient and public involvement policy. Available at: https://www.nice.org.uk/media/default/About/NICECommunities/Public-involvement/Patient-and-public-involvementpolicy/Patient-and-public-involvement-policy-November-2013.pdf.

Nicholls, T.L., Petersen, K.L., Brink, J., Webster, C. (2011). A clinical and risk profile of forensic psychiatric patients: treatment team STARTs in a Canadian service. International Journal of Forensic Mental Health, 10, 187199. doi: 10.1080/14999013.2011.600234.

Nijman, H., Merckelbach, H., Evers, C., Palmstierna T., Campo, J. (2002). Prediction of aggression on a locked psychiatric admissions ward. Acta Psychiatr Scand, 105, 390-395.

Nilsen, P., Ståhl, C., Roback, K., \& Cairney, P. (2013). Never the twain shall meet? A comparison of implementation science and policy implementation research. Implementation Science, 8, 63 .

Nilsson, T., Munthe, C., Gustavson, C., Forsman, A. \& Anckarsäter, H. (2009). The precarious practice of forensic psychiatric risk assessments. International Journal of Law and Psychiatry, 32, 400-407. doi:10.1016/j.ijlp.2009.09.010.

Nonstad, K., Webster, C.D. (2011). How to fail in the implementation of a risk assessment scheme of any other new procedure in your organization. American Journal of Orthopsychiatry, 81, 94-99.

Nonstad, K., Nesset, M.B., Kroppan, E., Pedersen, T.W., Nøttestad, J.A., Almvik, R., Palmstierna, T. (2010). The predictive validity and other properties of the Short Term Assessment of Risk and Treatability (START). International Journal of Forensic Mental Health, 9, 294-299. doi: 10.1080/14999013.2010.534958.

Olsson, H., Audulv, Å., Strand, S., Kristiansen, L. (2015). Reducing or increasing violence in forensic care: a qualitative study of inpatient experiences. Archives of Psychiatric Nursing, 29, 393-400. doi: 10.1016/j.apnu.2015.06.009.

O'Shea, L.E., Dickens, G.L. (2014). Short-Term Assessment of Risk and Treatability (START): systematic review and meta-analysis. Psychological Assessment, 26, 990-1002. doi: 10.1037/ao036794.

Patton, M.Q. (2002). Qualitative Research and Evaluation Methods. 3rd ed. London: Sage Publications. pp. 564-566.

Peay, J. (2009). Liberty and detention: Mental illness, dangerousness and protecting society. Social, ethical and legal aspects of psychiatry, Psychiatry, 8(12):490-492. doi: 10.1016/j.mppsy.2009.09.013.

Perrault, R.T., Paiva-Salisbury, M.A., Vincent, G.M. (2012). Probation officers' perceptions of youths' risk of reoffending and use of risk assessment in case management. Behavioural Sciences and the Law, 30, 487-505. 
Persson, M., Belfrage, H., Fredriksson, B., Kristiansson, M. (2017) Violence during imprisonment, forensic psychiatric care, and probation: correlations and predictive validity of the risk assessment instruments COVR, LSI-R, HCR-20V3, and SAPROF. International Journal of Forensic Mental Health, 16, 117-129. doi: 10.1080/14999013.2016.1266420.

Peterson, J., Skeem, J., Manchak, S. (2011). If you want to know, consider asking: how likely is it that patients will hurt themselves in the future? Psychological Assessment, 23, 626-634. doi: 10.1037/a0022971.

Pulsford, D., Crumpton, A., Bakers, A., Wilkins, T., Wright, K., Duxbury, J. (2013). Aggression in a high secure hospital: staff and patient attitudes. Journal of Psychiatric and Mental Health Nursing, 20, 296-304. doi: 10.1111/J.1365-2850.2012.01908.X.

Ramesh, T., Igoumenou, A., Vazquez Montes, M. \& Fazel, S. (2018). Use of risk assessment instruments to predict violence in forensic psychiatric hospitals: a systematic review and meta-analysis. European Psychiatry, 52, 4753 .

Reynolds, L., M., Jones, J., C., Davies, J., P., Freeth, D. \& Heymand, B. (2014). Playing the game: service users' management of risk status in a UK medium secure forensic mental health service. Health, Risk \& Society, 16 (3), 199-209. http://dx.doi.org/10.1080/13698575.2014.911820.

Risk Management Authority (2006). Standards and Guidelines for Risk Assessment. Version 1. Paisley, Scotland: Risk Management Authority.

Roaldset, J.O., Björkly, S. (2010). Patients 'own statements of their future risk for violent and self-harm behaviour: A prospective inpatient and post- discharge follow- up study in an acute psychiatric unit. Psychiatry Research, 178, 153-159. doi: 10.1016/j.psychres.2010.04.012.

Rogers, E.M. (1983). Diffusion of Innovations. 3rd ed.. New York: The Free Press.

Ryan, R.M., Deci, E.L. (2000). Intrinsic and extrinsic motivations: classic definitions and new directions. Contemporary Educational Psychology, 25, 54-67. doi: 10.1006/ceps.1999.1020.

SBU, Statens beredning för medicinsk och social utvärdering. Utvärdering av metoder $i$ hälso- och sjukvården och insatser $i$ socialtjänsten: En handbok, 2017, Stockholm.

Schuringa, E., Heininga, V., E., Spreen, M., Bogaerts, S. (2018). Concurrent and predictive validity of the Instrument for Forensic Treatment Evaluation: From risk assessment to routine, multidisciplinary treatment evaluation. International Journal of Offender Therapy and Comparative Criminology, 62 (5), 1281-1299. doi: 10.1177/0306624X16676100.

Scurich, N. (2016). An introduction to the assessment of violence risk. In: Singh, J.P., Björkly, S., Fazel, S. (Eds.), International Perspectives on Violence Risk Assessment. New York: Oxford University Press. doi: 10.1093/acprof:oso/9780199386291.003.0001

Singh, J.P., Grann, M., Fazel, S. (2011). A comparative study of violence risk assessment tools: A systematic review and metaregression analysis of 68 
studies involving 25,980 participants. Clinical Psychology Review, 31, 499-513. doi: 10.1016/j.cpr.2010.11.009.

Singh, J.P., Desmarais, S.L., Sellers, B.G., Hylton, T., Tirotti, M., Van Dorn, R.A. (2014a). From risk assessment to risk management: matching interventions to adolescent offenders' strengths and vulnerabilities. Children and Youth Services Review, 47, 1-9. doi: 10.1016/j.childyouth.2013.09.015.

Singh, J.P., Desmarais, S.L., Hurducas, C., Arbach-Lucioni, K., Condemarin, C., Dean, K., Doyle, M., Folino, J.O., Godoy-Cervera, V., Grann, M., Mei Yee Ho, R., Large, M.M., Hjort Nielsen, L., Pham, T.H., Rebocho, M.F., Reeves, K.A., Rettenberger, M., de Ruiter, C., Seewald, K., Otto, R.K. (2014b). International perspectives on the practical application of violence risk assessment: a global survey of 44 countries. International Journal of Forensic Mental Health, 13, 193-206. doi: 10.1080/14999013.2014.922141.

Singh, J.P., Bjørkly, S., Fazel, S. (2016). Comparing preferences for actuarial versus structured professional judgment violence risk assessment measures across five continents. To what extent is practice keeping pace with science? Nicholls, T.L., Petersen, K.L., Pritchard, M.M. (Eds.), International Perspectives on Violence Risk Assessment. New York: Oxford University Press. doi: 10.1093/acprof:oso/9780199386291.003.0008

Skeem, J.L., Manchak, S.M., Lidz, C.W., Mulvey, E.P. (2013). The utility of patients 'self-perceptions of violence risk: consider asking the person who may know best. Psychiatric Services, 64, 410-415. doi: 10.1176/appi.ps.001312012.

Slemon, A., Jenkins, E., Bungay, V. (2017). Safety in psychiatric inpatient care: The impact of risk management culture on mental health nursing practice. Nursing Inquiry, 24. doi.org/10.1111/nin.12199.

Socialdepartementet Patientdatalagen (2008). 2008:355.

Socialdepartementet SFS (2017). 2017:374, Lag (1991:1129) om rättspsykiatrisk vård.

SOSFS 2008:18. Socialstryelsens författningssamling. (The National Board of Health and Welfare Code of Statues). 2008. Psykiatrisk tvångsvård och rättspsykiatrisk vård. (Compulsory psychiatric care and forensic psychiatric care.). Stockholm. National Board of Health and Welfare.

SOU (2004). Riskbedömningar inom den specialiserade psykiatriska vården En kartläggning. www.socialstyrelsen.se.

SOU (2006). SOU2006:91. Nationell Psykiatrisamordning, Slutrapport och Förslag. Stockholm.

Storey, J.E., Watt, K.A., Hart, S.D. (2015). An examination of violence risk communication in practice using a structured professional judgment framework. Behavioral Sciences and the Law, 33, 39-55.

Storm, M., Edwards, A. (2013). Models of user involvement in the mental health context: intentions and implementation challenges. Psychiatric Quarterly, 84, 313-327. doi: 10.1007/s11126-012-9247-x. 
Sturup, J., Forsman, M., Haggård, U., Karlberg, D., Johansson, P. (2013). Riskbedömning i kriminalvård och rättspsykiatri (Sammanfattningsrapport 2013:269). Kriminalvården.

Sullivan, G.B.(2005). Forensic patients `accounts of risk: the case for qualitative research within a sociocultural theory framework. Australian Psychologist, 40, 31-44. doi: 10.1080/00050060412331295936.

Towl, G. (2005). Risk assessment. Evidence Based Mental Health EBMH notebook, http://ebmh.bmj.com.

Troquete, N.A.C., van den Brink, R.H.S., Beintema, H., Mulder, T., van Os, T.W.D.P. (2013a). Risk assessment and shared care planning in outpatient forensic psychiatry: cluster randomised controlled trial. British Journal of Psychiatry, 202, 365-371. doi: 10.1192/bjp.bp.112.113043.

Troquete, N.A.C., van den Brink, R.H.S., Beintema, H., Mulder, T., van Os, T.W.D.P. (2013b). Little evidence for the usefulness of violence risk assessment: author's reply. British Journal of Psychiatry, 202, 468-469. doi: 10.1192/bjp.202.6.468a.

van den Brink, R., H., S., Hooijschuur, A., van Os, T., W., D,, P., Savenije, W. \& Wiersma, D. (2010). Routine Violence Risk Assessment in Community Forensic Mental Healthcare. Behavioral Sciences and the Law, 28, 396-410. doi: $10.1002 / b s l .904$.

Vincent, G.M., Guy, L.S., Gershenson, B.G., McGabe, P. (2012a). Does risk assessment make a difference? Results of implementing the SAVRY in juvenile probation. Behavioural Sciences and the Law, 30, 384-405.

Vincent, G., Paiva-Salisbury, M.L., Cook, N.E., Guy, L.S., Perrault, R.T. (2012b). Impact of risk/needs assessment on juvenile probation officers 'decision making: importance of implementation. Psychology, Public Policy, and Law, 18, 549-576. doi: 10.1037/a0027186.

Vincent, G., M., Guy, L., S., Perrault, R., T., Gershenson, B. (2016). Risk assessment matters, but only when implemented well: A multisite study in juvenile probation. Law and Human Behavior, 40 (6), 683-696. http://dx.doi.org/10.1037/lhboooo214

Vojt, G. (2013). The Implementation of Violence Risk Assessments into Forensic Psychiatric Care in Scotland. Thesis, University of Edinburgh.

Vojt, G., Slesser, M., Marshall, L., Thomson, L. (2011). The clinical reality of implementing formal risk assessment and management measures within high secure forensic care. Medicine, Science and the Law, 51, 220-227. doi: 10.1258/msl.2011.010149.

Vojt, G., Thomson, L.D.G., Marshall, L.A. (2013). The predictive validity of the HCR-20 following clinical implementation: does it work in practice? Journal of Forensic Psychiatry \& Psychology, 24, 371-385. doi: 10.1080/14789949.2013.800894.

Wand, T. (2012). Investigating the evidence for the effectiveness of risk assessment in mental health care. Issues in Mental Health Nursing, 33, 2-7. doi: 10.3109/01612840.2011.616984. 
Wand, T., Large, M. (2013). Little evidence for the usefulness of violence risk assessment. British Journal of Psychiatry, 202, 468. doi: 10.1192/bjp.202.6.468.

Webster, C.D. (2011). From flipping the coin to seeing both its sides. Journal of Psychiatric Intensive Care, 7, 73-78.

Webster, C.D., Nicholls, T.L., Martin, M.L., Desmarais, S.L., Brink, J. (2006). Short-Term Assessment of Risk and Treatability (START): the case for a new structured professional judgment scheme. Behavioral Sciences and the Law, 24, 747-766. doi: 10.1002/bsl.737.

Webster, C.D., Douglas, K.S., Eaves, D., Hart, S.D. (1997). HCR-2O Assessing Risk for Violence (version 2). Mental Health, Law and Policy Institute, Simon Fraser University, British Columbia, Canada.

Webster, C.D., Martin, M.L., Brink, J., Nicholls, T.L., Middleton, C. (2004). Manual for the Short-Term Assessment of Risk and Treatability (START) (version 1.0). St. Joseph's Healthcare Hamilton, Ontario, Canada; Forensic Psychiatric Services Commission, Port Coquitlam, British Columbia, Canada.

Webster, C., D., Nicholls, T., L., Martin, M-L., Desmarais, S., L., Brink, J. (2006). Short-Term Assessment of Risk and Treatability (START): TheCase for a New Structured Professional Judgment Scheme. Behavioral Sciences and the Law, 24, 747-766. doi: 10.1002/bsl.737.

Webster, C.D., Martin, M.-L., Brink, J., Nicholls, T.L., Desmarais, S.L. (2010). Short-Term Assessment of Risk and Treatability (START) (version 1.1). St. Joseph's Healthcare Hamilton, Ontario, Canada; Forensic Psychiatric Services Commission, Port Coquitlam, British Columbia, Canada.

Whinship, G. (2014). A qualitative study into the attitudes of patients and staff towards violence and aggression in a high security hospital. Journal of Psychiatric and Mental Health Nursing, 21, 184-188. doi: 10.1111/jpm.12108.

Wibeck, V. (2010). Fokusgrupper - Om fokuserade gruppintervjuer som undersökningsmetod. Lund: Studentlitteratur.

Wolf, A., Whitington, D., Fazel, S. (2017). Violence Prevention in Psychiatry: An Umbrella Review of Interventions in General and Forensic Psychiatry. University of Oxford, Department of Psychiatry, Warneford Hospital, Oxford, UK.

Woods, P. Lasiuk, G.C. (2008). Risk prediction: a review of the literature. Journal of Forensic Nursing, 4, 1-11. doi: 10.1111/j.1939-3938.2008.00001.x.

World Health Organization (2005). Information Sheet. Mental Health and Prisoners. Geneva: International Committee of the Red Cross.

Wright, P., Webster, C.D. (2011). Implementing structured professional judgement risk assessment schemes: an example of institutional change. International Journal of Forensic Mental Health, 10, 1-6. doi: 10.1080/14999013.2011.552365. 
Yang, M., Wong, S., Coid, J. (2010). The efficacy of violence prediction: a metaanalytic comparison of nine risk assessment tools. Psychological Bulletin, 136, 740-767. doi: 10.1037/a0020473.

Young, D., Moline, K., Farrell, J., Bierie, D. (2006). Best implementation practices: disseminating new assessment technologies in a juvenile justice agency. Crime \& Delinquency, 52, 135-158. doi:

10.1177/0011128705281752. 


\section{Papers}

The papers associated with this thesis have been removed for copyright reasons. For more details about these see:

http://urn.kb.se/resolve?urn=urn:nbn:se:liu:diva-156726 



\section{FACULTY OF MEDICINE AND HEALTH SCIENCES}

Linköping University Medical Dissertation No. 1666, 2019

Department of Medical and Health Sciences

Linköping University

SE-581 83 Linköping, Sweden

www.liu.se 